\title{
Geomechanical Model Calibration Using Field Measurements for a Petroleum Reserve
}

\author{
Byoung Yoon Park ${ }^{1}$. Steven R. Sobolik ${ }^{1}$. Courtney G. Herrick ${ }^{1}$
}

Received: 22 February 2017 / Accepted: 29 November 2017 / Published online: 19 January 2018

(c) The Author(s) 2018. This article is an open access publication

\begin{abstract}
A finite element numerical analysis model has been constructed that consists of a mesh that effectively captures the geometries of Bayou Choctaw (BC) Strategic Petroleum Reserve (SPR) site and multimechanism deformation (M-D) salt constitutive model using the daily data of actual wellhead pressure and oil-brine interface location. The salt creep rate is not uniform in the salt dome, and the creep test data for BC salt are limited. Therefore, the model calibration is necessary to simulate the geomechanical behavior of the salt dome. The cavern volumetric closures of SPR caverns calculated from CAVEMAN are used as the field baseline measurement. The structure factor, $A_{2}$, and transient strain limit factor, $K_{0}$, in the M-D constitutive model are used for the calibration. The value of $A_{2}$, obtained experimentally from BC salt, and the value of $K_{0}$, obtained from Waste Isolation Pilot Plant salt, are used for the baseline values. To adjust the magnitude of $A_{2}$ and $K_{0}$, multiplication factors $A_{2} F$ and $K_{0} F$ are defined, respectively. The $A_{2} F$ and $K_{0} F$ values of the salt dome and salt drawdown skins surrounding each SPR cavern have been determined through a number of back analyses. The cavern volumetric closures calculated from this model correspond to the predictions from CAVEMAN for six SPR caverns. Therefore, this model is able to predict behaviors of the salt dome, caverns, caprock, and interbed layers. The geotechnical concerns associated with the BC site from this analysis will be explained in a follow-up paper.
\end{abstract}

Keywords Model calibration $\cdot$ Realistic geometries $\cdot$ Rock salt behavior $\cdot$ Petroleum Reserve

\section{Introduction}

\subsection{Background}

The US Strategic Petroleum Reserve (SPR) stores crude oil in 60 caverns located at four sites along the Gulf Coast. The reserve contains approximately 695 million barrels $\left(110 \mathrm{Mm}^{3}\right)$ of crude oil. Most of the caverns were solutionmined by the US Department of Energy (DOE) and are typified as cylindrical in shape. In reality, the geometry, spacing, and depths of the caverns are irregular. Sandia National Laboratories (hereafter 'Sandia'), on behalf of DOE, is

Byoung Yoon Park

bypark@sandia.gov

Steven R. Sobolik

srsobol@sandia.gov

Courtney G. Herrick

cgherri@ sandia.gov

1 Sandia National Laboratories, P.O. Box 5800, MS0751, Albuquerque, NM 87185, USA evaluating the mechanical integrity of the salt surrounding existing petroleum storage caverns in the Bayou Choctaw (BC) Salt Dome located in Louisiana.

Geotechnical concerns arose due to the close proximity of some of the caverns to each other (e.g., Caverns 15 and 17) or to the edge of salt (e.g., Cavern 20) (Park et al. 2008). In addition to the SPR caverns at BC, eight other caverns exist within the dome that store various hydrocarbons and are operated by private industry. Also, there are nine abandoned caverns, one of which collapsed in 1954 (Cavern 7) and another which is believed to be in a quasistable condition (Cavern 4). The integrity of wellbores at the interbed between the caprock and salt is another concern because oil leaks occurred at the interbed in the Big Hill site (Park 2014). When oil is withdrawn from a cavern in salt using freshwater, the cavern enlarges. As a result, the pillar separating caverns in the SPR fields is reduced over time due to usage of the reserve. The enlarged cavern diameters and smaller pillars reduce underground stability (Park et al. 2011). It is necessary to establish a limit for the remaining 
pillar thickness between caverns without threatening the structural integrity of the caverns.

DOE may increase the size of the reserve. The BC site is the smallest SPR site. The site is limited in its expansion capability due to the small size of the salt dome and other commercial storage operations in the dome. The SPR may expand the site's capacity through the development of two new caverns in existing SPR property (Park and Ehgartner 2012). The impacts of the expansion by two caverns on underground creep closure, surface subsidence, infrastructure, and well integrity need to be investigated using a highresolution numerical model.

\subsection{Objective}

Sandia uses large-scale, three-dimensional (3D) computational models to simulate the geomechanical behavior of underground storage facilities such as solution-mined caverns in a salt dome. Recent advances in the state of the art in geomechanics modeling have enabled $3 \mathrm{D}$ analyses to be performed. Three-dimensional analyses capture the actual geometry and layout of a cavern field and result in more realistic simulations. The complexities within the BC cavern field require such advanced simulations, as the field has a long history of development resulting in 26 caverns of various shapes, depths, and operational states. This paper attempts to describe how these conditions are modeled and addresses the resulting performance and stability issues.

This paper describes a series of geomechanical simulations of BC SPR. In the first paper of the series, Park et al. (2017) developed a three-dimensional finite element mesh capturing actual geometries of the $\mathrm{BC}$ site, which has been constructed using the sonar and seismic survey data obtained from the field. The mesh consists of hexahedral elements because the salt constitutive model is coded using these elements. As the second of the series, this paper describes the model calibration to match the analysis results to the field measurements. The next paper will provide solutions for the geotechnical concerns and impacts of the expansion mentioned in Sect. 1.1 and conclusions.

\section{Site Description}

In constructing a conceptual model, and then a computational geomechanical model, of the caverns in the $\mathrm{BC}$ dome, it is important to have and utilize as much information as possible regarding the caverns' geometries, histories, and locations within the salt dome. The BC salt dome, located in south-central Louisiana near Baton Rouge, was discovered in 1926. Since then, over 300 oil and gas wells were drilled into and around the dome, as well as numerous shallow holes drilled into the caprock. Since 1937, Allied Chemical
Corporation has drilled over 20 brine wells in the dome. In 1976, DOE purchased 11 of these leached caverns and was storing approximately 22 million barrels $\left(3.5 \mathrm{Mm}^{3}\right)$ of crude oil in three of the caverns (Caverns 15, 18, and 19 in Fig. 1), forming part of the SPR Program (Hogan 1980).

Since 1980, SPR Caverns 18, 19, and 20 were enlarged substantially; Union Texas Petroleum (UTP) Caverns 6 and 26 were constructed; and Caverns 101 and 102 were leached by DOE. Cavern 102 was traded to UTP in a swap for Cavern 17, now used for SPR oil storage. Cavern 102 has gone through several changes in ownership: first UTP, then Petrologistics, and finally Boardwalk. The DOE repurchased Cavern 102 from Boardwalk to use for SPR in 2012.

\section{Geometrical Conditions}

\subsection{Salt Dome}

The top of the dome lies between $600 \mathrm{ft}(183 \mathrm{~m})$ and $700 \mathrm{ft}$ $(213 \mathrm{~m})$ below the surface. The salt surface on the top of the dome is relatively flat, sloping gently outward to a depth of approximately $1000 \mathrm{ft}(305 \mathrm{~m})$ where the angle suddenly steepens sharply. The 3D seismic survey over the BC salt dome used in this study was originally shot in 1994, and the objective of the original processing appears to have been deep petroleum targets along the flanks of the salt dome (Rautman et al. 2009). Roberts (2015) generated the salt dome image using the seismic data and $4 \mathrm{DIM}^{1}$ tool as shown in Fig. 1 (left images). Park and Roberts (2015) and Park et al. (2017) constructed the three-dimensional finite element mesh of the dome region using the seismic data and the CUBIT mesh generation tool (Sandia 2015).

\subsection{Lithologies Surrounding the Salt Dome}

\subsubsection{Overburden}

The surface and near-surface sediments overlying the BC dome are of the Pleistocene to the Holocene age. The oldest sediments consist of proglacial sands and gravels with some clay layers. These sediments are overlain by an alternating sequence of sands, silts, and clays (Hogan 1980). The bottom of the overburden layer (as well as the surfaces of the caprock, interbed, and top of the dome) is not flat. In this study, however, the bottom is approximated as flat to avoid creating mesh elements with unfavorable geometries. The meshed overburden block that is $12,000 \mathrm{ft}(3658 \mathrm{~m})$ long, $11,000 \mathrm{ft}(3353 \mathrm{~m})$ wide, and $500 \mathrm{ft}(152 \mathrm{~m})$ thick. In this model, the thickness of each element layer is $20 \mathrm{ft}(6.1 \mathrm{~m})$,

\footnotetext{
${ }^{1}$ Four-Dimensional Interactive Model Player developed by C Tech.
} 


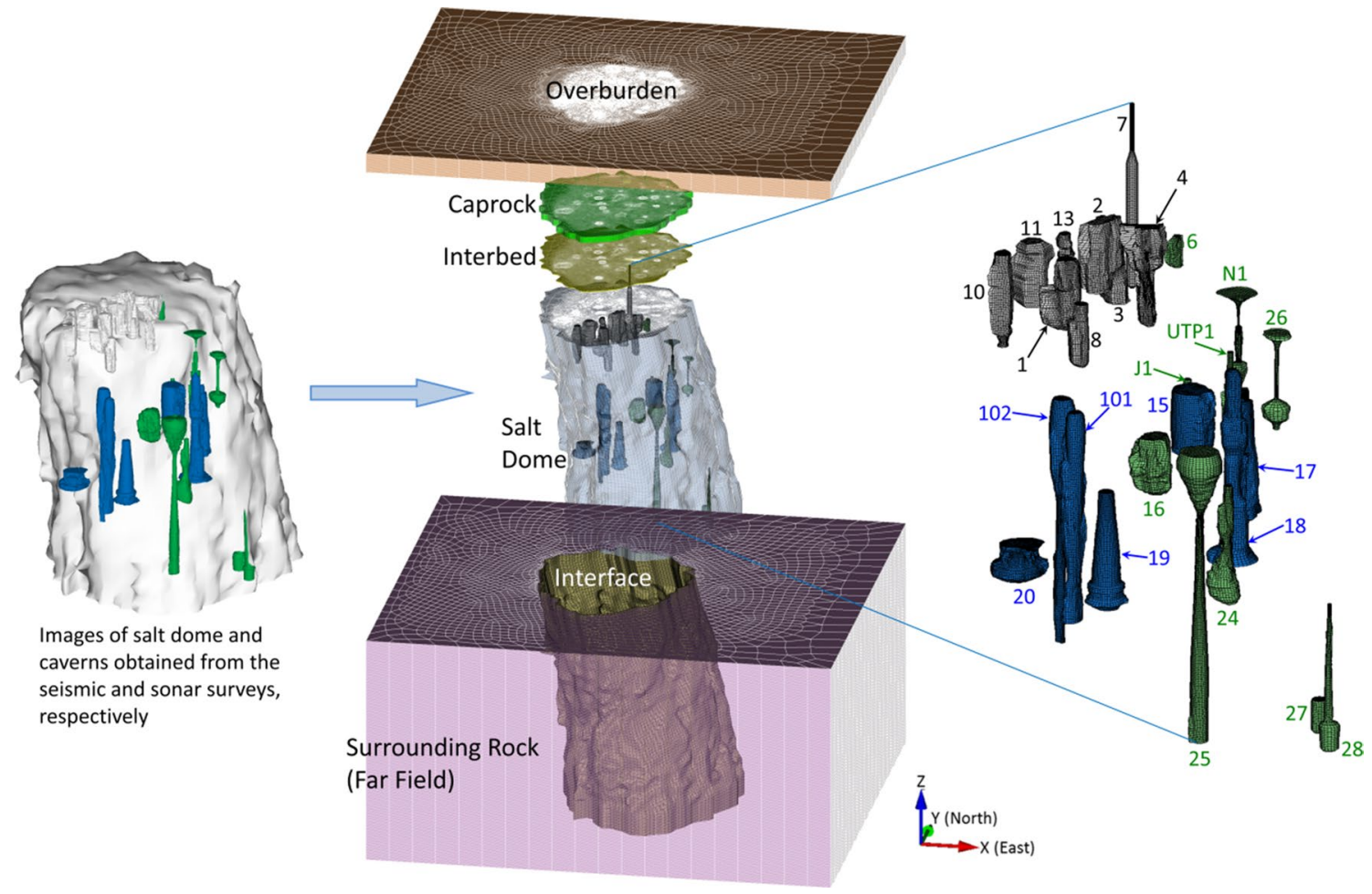

Fig. 1 Images of salt dome and caverns obtained from the seismic and sonar surveys, respectively, (left) and overview of the hexahedral finite element meshes of the stratigraphy and cavern field at Bayou Choctaw (Park and Roberts 2015; Park et al. 2017). The US Strate-

so the mesh has 25 element levels vertically as shown in Fig. 1.

\subsubsection{Caprock}

Two distinct zones are found in the caprock at the BC site: an upper zone, termed the clay and gypsum zone, and a lower zone, called the massive gypsum-anhydrite zone. The clay and gypsum zone is composed of layers of gypsum intercalated with clay. Faults and fractures in the caprock result in a highly permeable and discontinuous unit with little structural strength (Hogan 1980). The bottom of the caprock surface is based on the topography of the salt dome top. The actual caprock top and bottom are not flat. The uneven top and bottom may produce poorly shaped elements. To avoid a poor shape, the caprock is simplified as a flat slice block $160 \mathrm{ft}$ thick as shown in Fig. 1.

\subsubsection{Interbed}

An interbed layer is implemented in the BC model to represent the salt/caprock contact. The collapse zone, formed by salt dissolving and collapse at the salt/caprock contact, is a highly permeable and discontinuous unit with little gic Petroleum Reserve stores crude oil in the seven blue caverns. The other caverns are the Boardwalk caverns (green) and abandoned caverns (gray). The cavern ID numbers are also shown

structural strength (Hogan 1980). The contact zone is modeled by the thin, soft element layer interbed block to evaluate the caverns' geomechanical effect to examine wellbore deformation at the interbed between the salt top and caprock bottom. The real interbed between the salt dome and caprock is not flat. The thickness of interbed layer is assumed to be $20 \mathrm{ft}$ (Fig. 1).

\subsubsection{Interface Between Dome and Far Field}

The BC salt dome is a diapiric structure, which has penetrated Mesozoic through Quaternary sediments. As in other types of intrusions, the salt dome must displace the overlying sediments as it pushes upward. Any sediment deposited above the dome must be either pushed aside or lifted up, increasing the chance of damage occurring to the loosened material. The mechanical failure of the sediments surrounding the dome has caused faults to develop both radially from and tangentially to the dome in a series of graben-horst structures (Hogan 1980). To simulate the loosened material, an interface block was inserted between the dome and sediments surrounding the dome. As with the interbed block, a thin, soft layer of elements is used for the interface block 
Table 1 Elevations of cavern tops and bottoms, cavern volumes, and sonar survey dates

\begin{tabular}{|l|c|c|c|c|}
\hline Cavern ID & $\begin{array}{c}\text { Sonar survey } \\
\text { date }\end{array}$ & $\begin{array}{c}\text { Top elevation } \\
(\mathrm{m})\end{array}$ & $\begin{array}{c}\text { Bottom } \\
\text { elevation }(\mathrm{m})\end{array}$ & $\begin{array}{c}\text { Volume } \\
\left(\mathrm{m}^{3}\right)\end{array}$ \\
\hline BC-1 & $5 / 30 / 1980$ & -317 & -543 & $1,268,652$ \\
\hline BC-2 & $7 / 28 / 1983$ & -238 & -463 & $1,496,688$ \\
\hline BC-3 & $7 / 13 / 1977$ & -311 & -561 & 663,983 \\
\hline BC-4 & $7 / 30 / 2013$ & -195 & -512 & 973,949 \\
\hline BC-6 & $11 / 1 / 2006$ & -378 & -475 & 134,367 \\
\hline BC-7 & Collapsed in 1954 & -152 & -597 & 465,492 \\
\hline BC-8 & $5 / 31 / 1980$ & -396 & -597 & 886,244 \\
\hline BC-10 & $9 / 13 / 1973$ & -305 & -604 & $1,176,648$ \\
\hline BC-11 & $3 / 10 / 1978$ & -329 & -530 & 528,701 \\
\hline BC-13 & $8 / 13 / 1977$ & -341 & -567 & $2,566,309$ \\
\hline BC-15 & $4 / 15 / 2009$ & -792 & -994 & $1,785,682$ \\
\hline BC-16 & $6 / 28 / 2004$ & -799 & -981 & $1,768,044$ \\
\hline BC-17 & $4 / 16 / 2009$ & -792 & -1207 & $2,667,269$ \\
\hline BC-18 & $1 / 6 / 2009$ & -652 & -1268 & $1,879,731$ \\
\hline BC-19 & $4 / 14 / 2009$ & -908 & -1280 & $1,493,320$ \\
\hline BC-20 & $12 / 13 / 2013$ & -1164 & -1274 & 940,350 \\
\hline BC-24 & $4 / 17 / 1992$ & -945 & -1317 & $2,639,455$ \\
\hline BC-25 & $10 / 30 / 2007$ & -786 & -1725 & 380,848 \\
\hline BC-26 & $10 / 11 / 1996$ & -701 & -1012 & 208,848 \\
\hline BC-27 & $10 / 28 / 2007$ & -1811 & -1914 & 352,760 \\
\hline BC-28 & $10 / 29 / 2007$ & -1433 & -1902 & 188,570 \\
\hline BC-J1 & $7 / 27 / 2006$ & -872 & -1189 & 278,820 \\
\hline BC-N1 & $12 / 5 / 2003$ & -585 & -1061 & 238,590 \\
\hline BC-UTP & $10 / 14 / 2006$ & -725 & -1061 & $1,937,753$ \\
\hline BC-101 & $2 / 1 / 2005$ & -786 & -1457 & $1,526,682$ \\
\hline BC-102 & $2 / 22 / 2012$ & -805 & -1591 & 465,492 \\
\hline
\end{tabular}

Blue, green, and gray fonts indicate the SPR, Boardwalk, and abandoned caverns, respectively

between the dome and surrounding sediments (hereafter 'surrounding rock' or 'far field') as shown in Fig. 1.

\subsubsection{Far Field}

The BC salt dome lies within the Gulf Coast geosyncline, an area of sediment deposition from the Mesozoic era to the present. In the site area, the geosyncline contains up to $30,000 \mathrm{ft}$ (9144 $\mathrm{m}$ ) of silts, sands, shales, limestones, and evaporites. These sediments were deposited in a variety of sedimentary environments including desert basin, evaporating flat, ocean basin, and delta (Hogan 1980). For simplification, the rock surrounding the salt dome is assumed to be an isotropic, homogeneous, linear elastic material. The surrounding rock block encircles the interface, caprock, interbed, and salt dome blocks. The lengths of the confining boundaries are $11,000 \mathrm{ft}(3353 \mathrm{~m})$ in the
$\mathrm{N}-\mathrm{S}$ direction and 12,001 $\mathrm{ft}(3658 \mathrm{~m})$ in the $\mathrm{E}-\mathrm{W}$ direction. The sizes of the caverns are much smaller than the dome size. The model boundary distances (surrounding rock dimensions) can be regarded as being a sufficient distance away from the caverns such that fixed boundaries can be applied.

\subsection{Caverns}

\subsubsection{Sonar Data}

Table 1 lists the elevations of cavern top and bottom, cavern volumes, and the dates when the sonar data were obtained. The 3D hexahedral element meshes for 26 caverns constructed by Park and Roberts (2015) and Park et al. (2017) as shown in Fig. 1. 
Fig. 2 BC-1 cavern cavity and salt skin layer

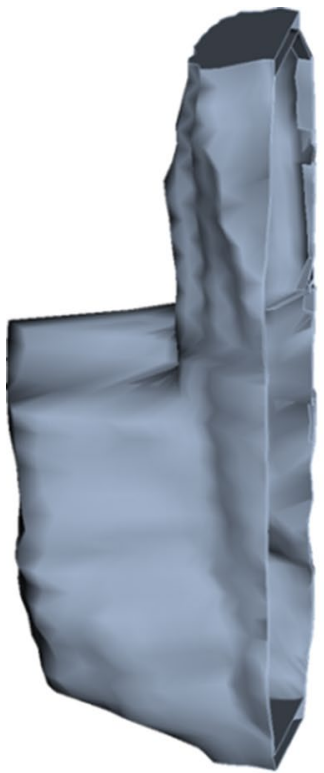

Extra Skin

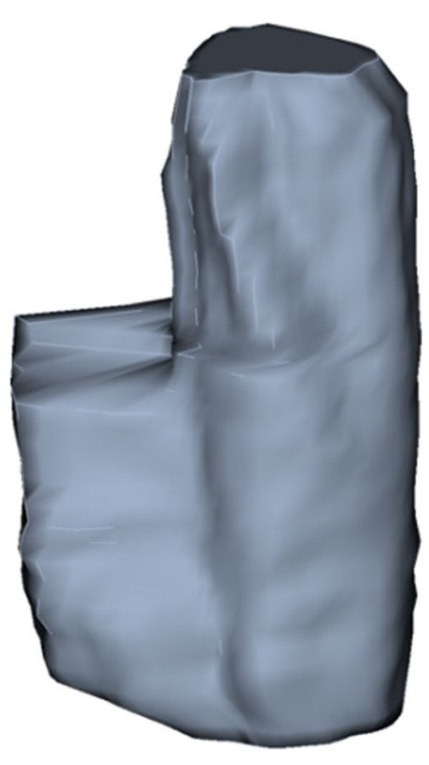

Cavern Cavity
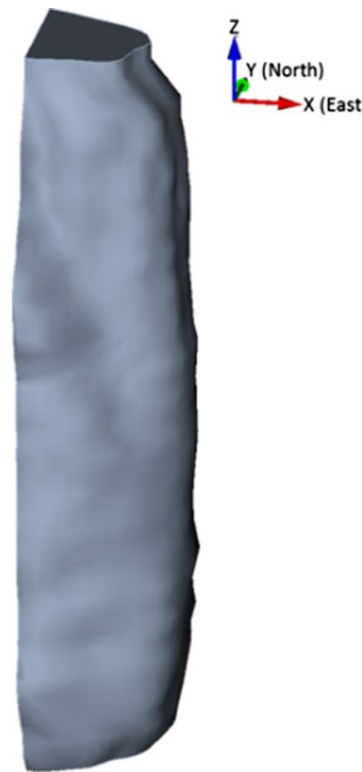

Extra Skin

\subsubsection{Non-SPR Caverns}

Figure 2 shows the BC-1 cavern cavity with an extra skin (layer of elements) as an example of a typical non-SPR cavern. The non-SPR caverns, because they are abandoned and private caverns, do not require the explicit meshing of a drawdown ${ }^{2}$ leach. However, the extra skin is constructed to check the analysis results at the cavern wall, roof, and floor. The cavern skin can be separated from the entire mesh. The amount of numerical output data in the skin block is much less than in the whole mesh. Examining the result in the skin volumes makes storage and analysis efforts more efficient. The small amount of the data can be handled easily to check various structural behaviors of the cavern. For the same reason, every cavern has an extra skin as the outmost layer. The detailed steps and methodologies to construct the cavern meshes are provided by Park and Roberts (2015).

\subsubsection{SPR Caverns}

Modeling of the leaching process of the caverns is performed by deleting a pre-meshed layer of elements along the walls of the cavern so that the cavern volume is increased by $15 \%$ per drawdown. As an example, Fig. 3 shows the volumes for SPR Cavern 18 as developed from sonar data, along with drawdown skins (leaching layers) and extra skin.

\footnotetext{
2 'Drawdown' is when the crude oil is withdrawn from the cavern. Fresh water injection is used to withdraw the crude oil. Because the cavern enlarges due to salt dissolving from the cavern walls, it is called a 'drawdown leach.
}

In this simulation, each SPR cavern is modeled as having five drawdown layers to be removed to account for the future oil drawdown activities. The SPR has a federal requirement for drawdown readiness to know the number of drawdowns a cavern may undergo and maintain cavern stability; it is current SPR policy to assume a maximum of five drawdowns unless geomechanical analyses or other technical considerations suggest a smaller number. The actual leaching process occurs over several days or weeks and usually removes more material from the bottom of the cavern than the top due to the entry point of water from the hanging string. Because of the relatively short time duration, this process is simplified in this finite element model to the instantaneous deletion of the pre-meshed drawdown block. The geometry of the leached layer is assigned a uniform $15 \%$ increase in radial area at each 20 -foot vertical interval to simplify the meshing process; future analyses may consider more realistic leached geometries.

\section{Mechanical Conditions}

\subsection{Assumptions}

In any numerical simulation of physical processes, it is frequently necessary to invoke a number of assumptions which render the analysis tractable. Analyses involving geologic materials are well known to be very challenging due to the extreme variability of rock quality (e.g., degree of fracturing) and the inability to fully characterize the in situ response of the rock when subjected to events such as leaching and mining. While laboratory tests can be 


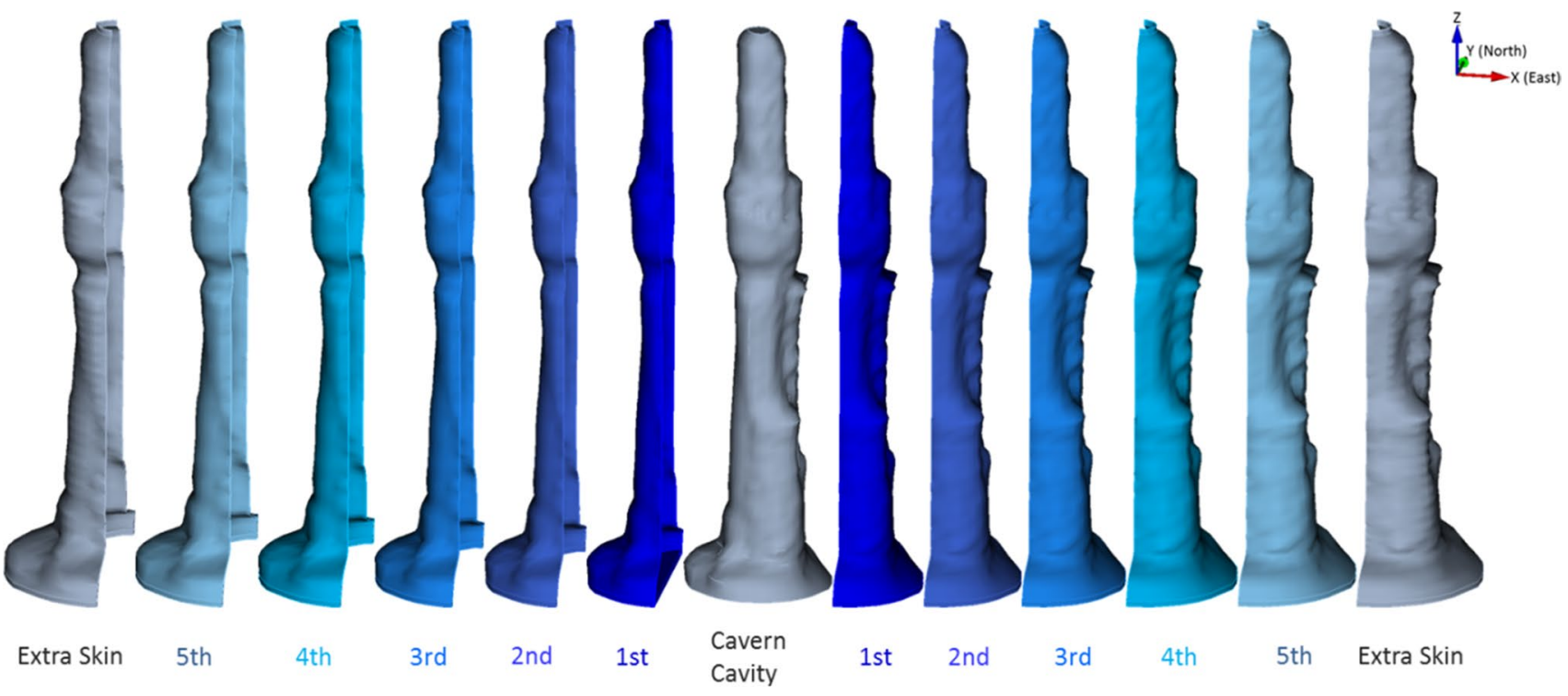

Fig. 3 BC-18 cavern cavity with five drawdown skins (leaching layers) and an extra skin

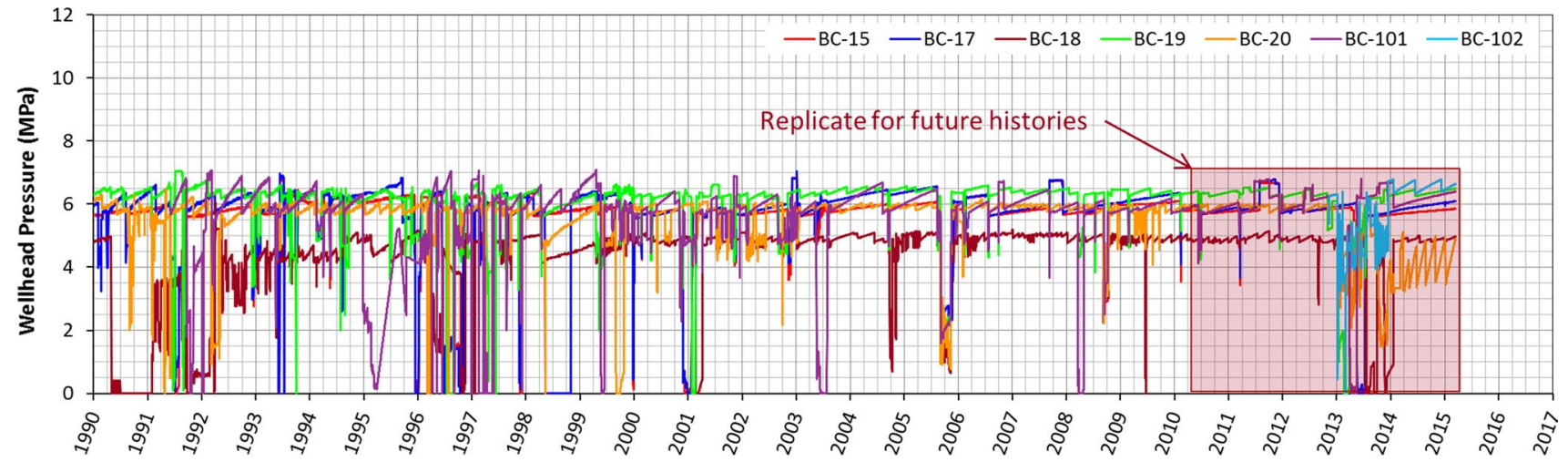

Fig. 4 Wellhead pressure histories for the seven Bayou Choctaw SPR caverns

performed under controlled conditions to give insight into the stress-strain behavior, there are always questions about the degree of sample disturbance caused during the retrieval of the sample from the ground or even the relevance of the tests since the laboratory samples do not usually incorporate features such as discontinuities.

The finite element mesh developed for these analyses represents a region 3658 by $3353 \mathrm{~m}$ (12,000 by $11,000 \mathrm{ft})$ in lateral dimension and extending vertically from the ground surface down to the depth of $1951 \mathrm{~m}(6400 \mathrm{ft})$. There are various assumptions for the computer simulations documented in this section:

- Use the simplified geometry of the planar layer for each interface between the lithologies.

- All materials are assumed to be isotropic and homogeneous.
- Use the material properties of sand for the interbed between the caprock and salt.

- A thin, soft layer of elements is used for the interface block between the dome and surrounding rock.

- Use a thickness of $20 \mathrm{ft}$ for the interbed between the caprock and salt.

- Apply a simplified workover cycle (5 years) to all caverns.

- Every lithology is bonded to each other.

\subsection{Wellhead Pressure}

\subsubsection{SPR Caverns}

The modeling simulates a cavern's responses forward in time from the cavern's initial creation. The real wellhead 
Table 2 Products held within Boardwalk caverns and pressure gradient of depth

\begin{tabular}{lll}
\hline Cavern ID & Product & $\begin{array}{l}\text { Pressure gradient } \\
\text { of depth }(\mathrm{Pa} / \mathrm{m})\end{array}$ \\
\hline BC-6 & Propylene & $5044(0.22 \mathrm{psi} / \mathrm{ft})$ \\
BC-16, N1, UTP1 & Ethylene & $12,288(0.54 \mathrm{psi} / \mathrm{ft})$ \\
BC-24 & Natural gas & $4163(0.18 \mathrm{psi} / \mathrm{ft})$ \\
BC-J1 & Ethane & $5592(0.25 \mathrm{psi} / \mathrm{ft})$ \\
BC-25, 26, 27, 28 & Brine & $11,768(0.52 \mathrm{psi} / \mathrm{ft})$ \\
\hline
\end{tabular}

histories of BC-15, 17, 18, 19, and 20 were recorded at the field office from 1/1/1990. They are shown in Fig. 4. For the purposes of the present simulation, it is assumed that the initial leaching of the caverns started on 1/1/1989. The analysis simulates caverns that were leached to full size over a 1-year period by means of gradually switching from salt to freshwater in the caverns. It was assumed that the SPR caverns were filled with petroleum 1 year after their initial leaches start. The caverns are simulated as creeping for the entire simulation period. The wellhead pressure of BC-101 was recorded from 6/1/1991, so it is assumed that the initial leach of BC-101 started on 6/1/1990 due to an assumed 1-year leaching period. BC-102 was previously filled with ethane and owned by Boardwalk. In 2012, the DOE purchased $\mathrm{BC}-102$ to use for SPR, and the wellhead pressure has been recorded since 11/9/2012. In this simulation, it is assumed that the wellhead pressure was a constant $6.2 \mathrm{MPa}$ (900 psi) during Boardwalk's operations until 11/8/2012, and then, the recorded wellhead pressure since 11/9/2012 is applied.

The most recent 5-year (3/20/2010-3/19/2015) wellhead pressure history of each cavern was replicated to simulate the next 5 years in which no drawdown is assumed to take place, and the five future times drawdown cycles thereafter. Before a cavern's initial leach starts, the model has a stabilization period (1/1/1900-12/31/1988). The model is then allowed to consolidate with gravity during the stabilization period.

\subsubsection{Boardwalk Caverns}

BC-6, 16, 24, 25, 26, 27, 28, J1, N1, and UTP1 are owned by Boardwalk. We have no access to the Boardwalk pressure data at this time. In this simulation, it is assumed that the initial leaching of the caverns started on 1/1/1989. The analysis simulates caverns that were leached to full size over a 1-year period by means of gradually switching from salt to freshwater in the caverns. The caverns are simulated as creeping for the entire simulation period. The wellhead pressure is assumed to be a constant $6.2 \mathrm{MPa}$ over the simulation time. The products held within Boardwalk caverns, and

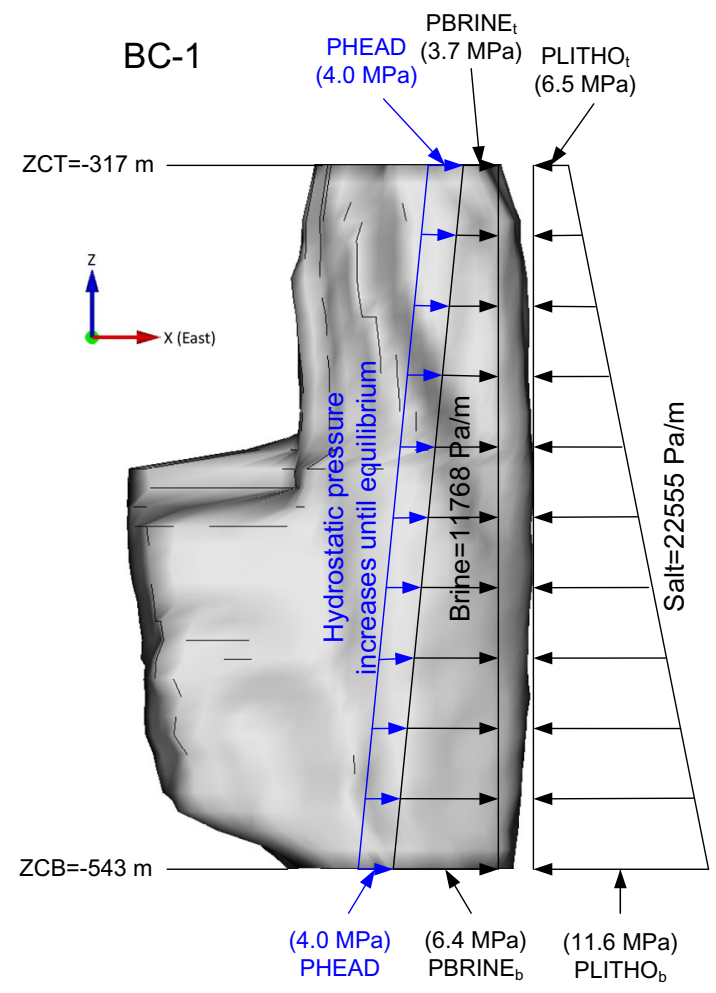

Fig. 5 Pressure distribution at equilibrium after plugging in BC-1

their pressure gradients with depth applied in the analysis are listed in Table 2.

\subsubsection{Abandoned Caverns}

The abandoned caverns are all plugged with the exception of BC-4. The wellheads were cut off below the surface and buried. BC-4 still has a wellhead and is actively monitored with sonar surveys and well-logging runs. It cannot hold fluid due to communication with the caprock, so zero wellhead pressure is applied in the analysis conservatively.

The abandoned caverns were filled fully with brine before plugging. Figure 5 shows pressure distributions on the inside and outside of BC- 1 at equilibrium after plugging as an example. The lithostatic pressure gradient with depth $(22,555 \mathrm{~Pa} / \mathrm{m})$ is larger than the brine pressure gradient $(11,768 \mathrm{~Pa} / \mathrm{m})$. The gradient difference drives the cavern volumetric closure due to salt creep. The brine volume does not decrease over time because there are no leaks; however, the cavern volume decreases due to creep. This causes the hydrostatic pressure in the cavern to increases until it comes into pressure equilibrium with the creeping salt. The pressure head, which is an additional hydrostatic pressure due to the cavern volumetric closure, is calculated to be $4.0 \mathrm{MPa}$ at equilibrium. In the same manner, the pressure heads of the abandoned caverns at equilibrium state are calculated as 
Table 3 Calculated pressure heads for the abandoned caverns at equilibrium state

\begin{tabular}{|c|c|c|c|c|c|c|c|}
\hline Cavern ID & $\begin{array}{l}\text { Depth of } \\
\text { cavern top } \\
\text { (m) }\end{array}$ & $\begin{array}{l}\text { Depth of } \\
\text { cavern bot- } \\
\text { tom }(\mathrm{m})\end{array}$ & $\begin{array}{l}\text { Lithostatic pressure } \\
\text { at cavern top (MPa) }\end{array}$ & $\begin{array}{l}\text { Lithostatic pressure } \\
\text { at cavern bottom } \\
(\mathrm{MPa})\end{array}$ & $\begin{array}{l}\text { Brine pressure at } \\
\text { cavern top (MPa) }\end{array}$ & $\begin{array}{l}\text { Brine pressure } \\
\text { at cavern bottom } \\
(\mathrm{MPa})\end{array}$ & $\begin{array}{l}\text { Pressure head at } \\
\text { equilibrium (MPa) }\end{array}$ \\
\hline BC-1 & -317 & -543 & 6.5 & 11.6 & 3.7 & 6.4 & 4.0 \\
\hline BC-2 & -238 & -463 & 4.7 & 9.8 & 2.8 & 5.5 & 3.1 \\
\hline BC-3 & -311 & -561 & 6.4 & 12.0 & 3.7 & 6.6 & 4.0 \\
\hline BC- 8 & -396 & -597 & 8.3 & 12.8 & 4.7 & 7.0 & 4.7 \\
\hline BC-10 & -305 & -604 & 6.2 & 13.0 & 3.6 & 7.1 & 4.2 \\
\hline BC-11 & -329 & -530 & 6.8 & 11.3 & 3.9 & 6.2 & 4.0 \\
\hline BC-13 & -341 & -567 & 7.0 & 12.1 & 4.0 & 6.7 & 4.2 \\
\hline
\end{tabular}

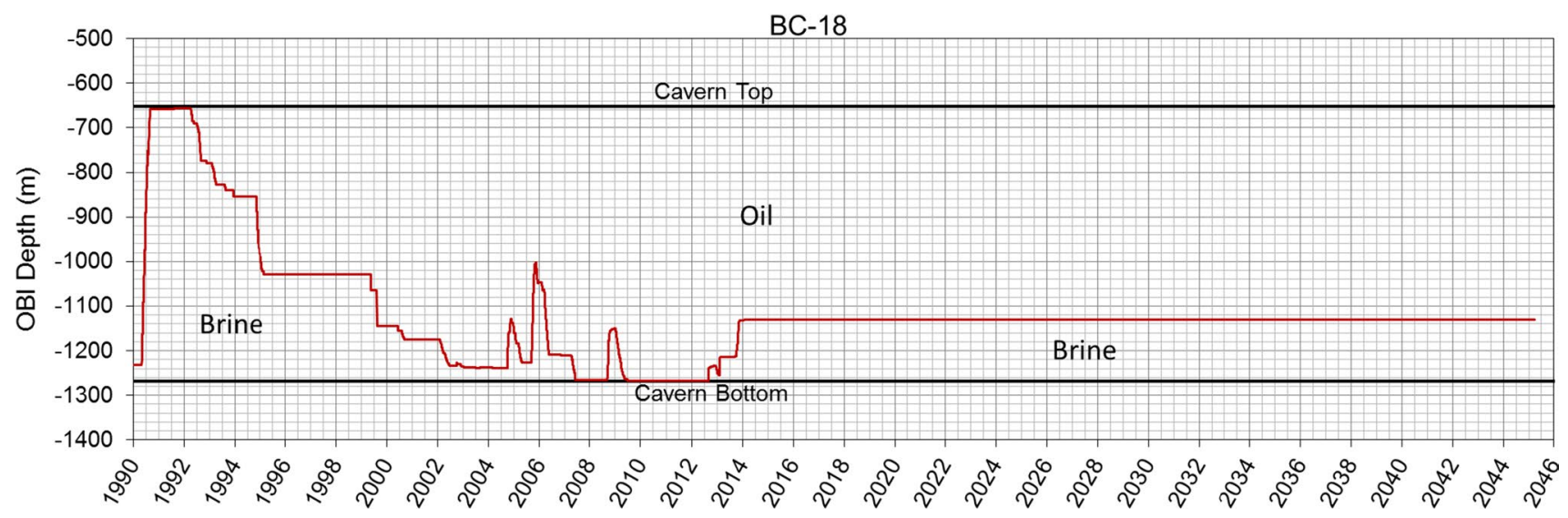

Fig. 6 Oil-brine interface depth history to apply into the simulation for BC-18

listed in Table 3. These values are used over time as wellhead pressures in the analysis.

Although there are no more pressure increases after equilibrium is reached, pressure differences do occur on the top and bottom of the cavern due to gradient with depth. Therefore, the bottom area shrinks (10.4 vs. $11.6 \mathrm{MPa}$ ), while the top area expands ( 7.7 vs. $6.5 \mathrm{MPa}$ ), so a risk of fracturing in the roof could occur.

\subsection{Oil-Brine Interface}

The caverns were not always fully filled with oil. Brine filled the bottom of cavern, and the portion changes with time depending on cavern operations. The difference between pressure gradients of oil $(8370 \mathrm{~Pa} / \mathrm{m}$ of depth $)$ and brine $(11,768 \mathrm{~Pa} / \mathrm{m}$ of depth) cannot be ignored. So, the amounts of oil and brine in a cavern over time need to be considered. Figure 6 shows the oil-brine interface (OBI) depth history of BC-18 as an example used in this analysis. The history data (1/1/1990-3/19/2015) were obtained from the field office. It is assumed that the OBI depth of each cavern does not change after $3 / 19 / 2015$ for the future simulation (3/20/2015-3/19/2045).

\subsection{Temperature}

The finite element model includes a depth-dependent temperature gradient which starts at $84.0{ }^{\circ} \mathrm{F}\left(28.9{ }^{\circ} \mathrm{C}\right)$ at the surface and increases at the rate of $1.38{ }^{\circ} \mathrm{F} / 100$ $\mathrm{ft}\left(2.51{ }^{\circ} \mathrm{C} / 100 \mathrm{~m}\right)$. The temperature profile is based on the average temperature data recorded in well logs from $\mathrm{BC}$ prior to leaching (Ballard and Ehgartner 2000). The temperature distribution is important because the creep response of salt is temperature dependent. Radial temperature gradients due to cavern cooling effects from the cavern contents are not considered in these calculations. Previous 2D cavern studies have shown the predicted cavern deformation to be insensitive to the developed radial thermal gradients (Hoffman 1992). 


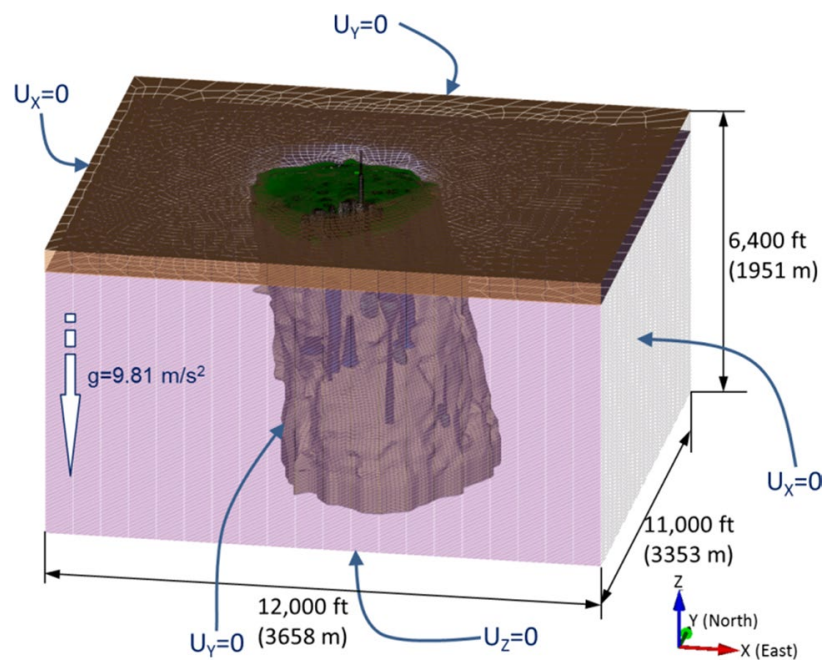

Fig. 7 Boundary conditions of Bayou Choctaw Model

\subsection{Boundary Condition}

Figure 7 shows the assembled mesh and the boundary conditions. The mesh consists of 7796,127 nodes and 7758,720 elements with 170 element blocks, three node sets (on the boundaries of the entire mesh to enforce zero normal displacement boundary conditions), and 55 side sets (on the interior surfaces of the caverns and skin layers to enforce cavern pressure boundary conditions). The lengths of the confining boundaries are $11,000 \mathrm{ft}(3353 \mathrm{~m})$ in the $\mathrm{N}-\mathrm{S}$ direction and $12,001 \mathrm{ft}$ $(3658 \mathrm{~m})$ in the $\mathrm{E}-\mathrm{W}$ direction. The boundary dimensions were selected to be more than two times the dome's range in each direction. The salt dome is modeled as being subject to regional far-field stresses acting from an infinite distance away. The sizes of the caverns are horizontally much smaller than the dome. Therefore, the north and south sides of far-field boundary are fixed in Y-direction, and the east and west sides are fixed in X-direction. The bottom is fixed vertically. The top surface and four sides are vertically free. The acceleration of gravity used in the model is $9.81 \mathrm{~m} / \mathrm{s}^{2}\left(32.174 \mathrm{ft} / \mathrm{s}^{2}\right)$.

\section{Material and Properties}

\subsection{Salt}

The M-D model proposed by Munson and Dawson (1979, 1982, 1984) and extended by Munson et al. (1989) has been included in $\mathrm{ADAGIO}^{3}$ to model the creep behavior of rock salt. Creep is envisioned as arising from the contributions of

\footnotetext{
${ }^{3}$ ADAGIO is the most recent Sandia-developed 3D solid mechanics code. It is written for parallel computing environments, and its solvers allow for scalable solutions of very large problems. ADAGIO
}

three appropriate micromechanical mechanisms as determined from salt deformation mechanism map (Munson 1979). These mechanisms are (1) a dislocation climb-controlled creep mechanism at high temperatures and low stresses, (2) an empirically specified, but undefined mechanism at low temperatures and low stresses, and (3) a dislocation slip-controlled mechanism at high stresses (Munson et al. 1989). These mechanisms act in parallel, which means the individual steady-state creep rates can be summed over the three mechanisms to give the total steady-state creep rate, as follows (Munson 1998):

$\dot{\varepsilon}_{\mathrm{s}}=\sum_{i=1}^{3} \dot{\varepsilon}_{\mathrm{s}_{i}}$

The steady-state creep rates for the individual mechanisms, respectively, are given by:

$\dot{\varepsilon}_{\mathrm{s}_{1}}=A_{1} \mathrm{e}^{-\frac{Q_{1}}{R T}}\left[\frac{\sigma}{\mu(1-\omega)}\right]^{n_{1}}$

$\dot{\varepsilon}_{\mathrm{S}_{2}}=A_{2} \mathrm{e}^{-\frac{Q_{2}}{R T}}\left[\frac{\sigma}{\mu(1-\omega)}\right]^{n_{2}}$

$\dot{\varepsilon}_{\mathrm{s}_{3}}=\left|H\left(\sigma-\sigma_{0}\right)\right|\left(B_{1} e^{-\frac{Q_{1}}{R T}}+B_{2} e^{-\frac{Q_{2}}{R T}}\right) \sinh \left[\frac{q\left(\frac{\sigma}{1-\omega}-\sigma_{0}\right)}{\mu}\right]$

where the numerical subscripts refer to the appropriate mechanism, the $A$ 's and $B$ 's are structure factors, $Q$ 's are activation energies, $R$ is the universal gas constant, $T$ is the absolute temperature, $\mu$ is the shear modulus, $q$ is the stress constant, $\sigma_{0}$ is a stress limit, and $H$ is a Heaviside step function with argument $\left(\sigma-\sigma_{0}\right)$. It has been shown (Munson et al. 1989) through multiaxial experiments that the proper equivalent stress measure is $\sigma=\left|\sigma_{1}-\sigma_{3}\right|$.

The equivalent total strain rate is treated through a multiplier on the steady-state rate, as

$\dot{\varepsilon}_{\mathrm{eq}}=F \dot{\varepsilon}_{\mathrm{s}}$

where the multiplier involves three branches of the transient creep curve: work hardening, steady state, and recovery, respectively, as follows:

$F= \begin{cases}\mathrm{e}^{\Delta\left(\left(1-\frac{\zeta}{\varepsilon_{t}^{*}}\right)^{2}\right)} ; & \zeta<\varepsilon_{\mathrm{t}}^{*} \\ 1 ; & \zeta=\varepsilon_{\mathrm{t}}^{*} \\ \mathrm{e}^{-\delta\left(\left(1-\frac{\zeta}{\varepsilon_{t}^{*}}\right)^{2}\right)} ; & \zeta>\varepsilon_{\mathrm{t}}^{*}\end{cases}$

Footnote 3 (continued)

uses the SIERRA framework, which allows for coupling with other SIERRA mechanics codes. 
here $\Delta$ is the work-hardening parameter, $\delta$ is the recovery parameter, $\zeta$ is the state parameter, and $\varepsilon_{t}^{*}$ is the transient strain limit. The state parameter rate is given by

$\dot{\zeta}=(F-1) \dot{\varepsilon}_{\mathrm{s}}$

The transient strain limit is defined by

$\varepsilon_{\mathrm{t}}^{*}=K_{0} \mathrm{e}^{c T}\left(\frac{\sigma}{\mu(1-\omega)}\right)^{m}$

where $K_{0}$ and $c$ are constants and $m$ is a material constant.

The work-hardening, $\omega$, and recovery, $\gamma$, parameters are described through linear functions, as follows:

$\Delta=\alpha_{\omega}+\beta_{\omega} \log \frac{\sigma}{\mu(1-\omega)}$

$\delta=\alpha_{\gamma}+\beta_{\gamma} \log \frac{\sigma}{\mu(1-\omega)}$

where the $\alpha$ 's and $\beta$ 's are constants. $\omega$ is the damage parameter, although throughout these equations it is taken as zero; there are currently insufficient data to reliably assign a nonzero value to, and thus, damage is considered during the postprocessing calculations using various published salt damage criteria based on first and second invariants of stress (Park et al. 2008).

Fundamentally, salt creep behavior has common micromechanical constitutive features regardless of the origin of the salt; all that differs is the exact value of the parameters. In particular, those critical parameters that primarily distinguish one salt material from another salt material are the steady-state responses as represented by the structure factors ( $A$ 's and $B$ 's) and the transient strain rate limits $\left(\varepsilon_{\mathrm{t}}^{*}\right)$ as represented by $K_{0}$ (Munson 1998).

The creep response from one specimen of the BC salt prepared from core obtained from Well 19A was determined using an incremental stress and temperature change procedure (Wawersik and Zeuch 1984). This material was medium-grained, with the maximum grain size of $19 \mathrm{~mm}$ and with uniformly distributed anhydrite crystals as the principal impurity. As a consequence, the BC material appears to be more creep resistant than the WIPP clean salt by about a factor of 0.17 . By applying ratios determined from the creep results, we can establish some suggested M-D creep parameters. However, the limited database permits only structure factors to be determined; all other parameters were established on the basis of the clean WIPP salt database and the logical extension of the WIPP parameters, considering how material variation can affect the parameter. These results are given in Table 4 for clean WIPP salt and the BC salt (Munson 1998). $A_{2} F$ is defined as $A_{2}$ multiplication factor to examine the $A_{2}$ factor effect, and $K_{0} F$ is defined as $K_{0}$ multiplication factor to examine the $K_{0}$ factor effect in Table 4.

\subsection{Lithologies Encompassing Salt}

An elastic model is assumed for the lithologies encompassing the salt dome. The surface overburden layer, which is mostly comprised of sand, is assumed to exhibit elastic material behavior. The sand layer is considered isotropic and has no assumed failure criteria. The values of the required model parameters for the overburden are not available for BC, so McCormick Ranch Sand properties were used. The caprock layer, consisting of gypsum, anhydrite, and sand, is also assumed to behave elastically. Samples of caprock from core holes at BC were tested by Dames and Moore (1978) to determine physical properties. Anisotropy of caprock will be considered if field behavior indicates significant variance with model predictions in future analysis. The rock surrounding the salt dome is sedimentary rock that consists mostly of sandstone and shale, which is assumed isotropic, homogeneous, elastic rock. The values of the required model parameters of the surrounding rocks are also not available. Typical values for the Young's moduli of sandstones and shales range from 0.4 to $69 \mathrm{GPa}$ (Carmichael 1984). For simplifying the analysis, a median value of the Young's modulus of sandstone, $35 \mathrm{GPa}$, is assumed because the surrounding rock behavior does not significantly affect the model results. The mechanical properties used in the present analysis are listed in Table 5. The external force and pressure applied to the model are gravity and internal pressure change in each cavern. The vertical stresses are calculated using gravity and density of each lithology with depth. The horizontal stresses are calculated using the equation of relationship between vertical stresses and Poisson's ratio.

\subsection{Interbed and Interface}

The interbed and interface are pseudo-materials, which represent contact surface. ADAGIO has a contact surface algorithm for modeling contact and sliding behavior between two solid surfaces. However, this algorithm has a limitation on the number of elements in the model. The current model is over that limitation. In place of a contact surface, a thin, soft layer of elements is used for the interbed between the caprock and salt top. The thin, soft element layer uses the overburden material properties and is assumed to behave mechanically like a contact surface with friction coefficient of 0.2 from a perspective of relative displacement between two lithologies. Thus, the overburden material properties (Table 6) are used for the interbed layer.

The interface between the dome and surrounding rock is a vertical layer, while the interbed is a horizontal layer. In this analysis, it is assumed that the interface behaves like a thin, soft element layer in a manner similar to the interbed, but the horizontal pressure applied on the dome surface has to be the same as it arises from the surrounding rock. Therefore, 
Table 4 Suggested parameter values for the M-D model of Bayou Choctaw salt (Munson 1998)

\begin{tabular}{|c|c|c|c|c|c|}
\hline Mechanism & Parameter & Symbol & Unit & WIPP salt baseline & BC salt \\
\hline Conventional & Density & $\rho$ & $\mathrm{kg} / \mathrm{m}^{3}$ & 2300 & 2300 \\
\hline \multirow[t]{3}{*}{ Elasticity } & Young's modulus & $E$ & $\mathrm{GPa}$ & 31.0 & 31.0 \\
\hline & Shear modulus & $\mu$ & $\mathrm{GPa}$ & 12.4 & 12.4 \\
\hline & Poisson's ratio & $\nu$ & - & 0.25 & 0.25 \\
\hline \multirow{3}{*}{$\begin{array}{l}\text { Dislocation climb-controlled creep mechanism at high tem- } \\
\text { peratures and low stresses (Eq. 2) }\end{array}$} & Structure factor & $A_{1}$ & $1 / \mathrm{s}$ & $8.386 \times 10^{22}$ & $1.445 \times 10^{22}$ \\
\hline & Activation energy & $Q_{1}$ & $\mathrm{cal} / \mathrm{mol}$ & 25,000 & 25,000 \\
\hline & Stress exponent & $n_{1}$ & - & 5.5 & 5.5 \\
\hline \multirow{3}{*}{$\begin{array}{l}\text { Empirically specified but undefined mechanism at low tem- } \\
\text { peratures and low stresses (Eq. 3) }\end{array}$} & Structure factor & $A_{2}$ & $1 / \mathrm{s}$ & $9.672 \times 10^{12}$ & $1.667 \times 10^{12} \times A_{2} F^{\mathrm{a}}$ \\
\hline & Activation energy & $Q_{2}$ & $\mathrm{cal} / \mathrm{mol}$ & 10,000 & 10,000 \\
\hline & Stress exponent & $n_{2}$ & - & 5.0 & 5.0 \\
\hline \multirow[t]{4}{*}{ Dislocation slip-controlled mechanism at high stresses (Eq. 4) } & Structure factor & $B_{1}$ & $1 / \mathrm{s}$ & $6,086,000$ & $1,048,941$ \\
\hline & Structure factor & $B_{2}$ & $1 / \mathrm{s}$ & 0.03034 & 0.005229 \\
\hline & Stress limit & $\sigma_{0}$ & MPa & 20.57 & 20.57 \\
\hline & Stress constant & $q$ & - & 5335 & 5335 \\
\hline \multirow[t]{3}{*}{ Transient strain (Eq. 8) } & Material constant & $m$ & - & 3.0 & 3.0 \\
\hline & Constant & $K_{0}$ & - & 627,500 & $627,500 \times K_{0} F^{\mathrm{b}}$ \\
\hline & Constant & $c$ & $1 / \mathrm{K}$ & 0.009198 & 0.009198 \\
\hline \multirow[t]{4}{*}{ Work hardening and recovery (Eqs. 9, 10) } & Constant & $\alpha$ & - & -17.37 & -17.37 \\
\hline & Constant & $\beta$ & - & -7.738 & -7.738 \\
\hline & Recovery & $\delta$ & - & 0.58 & 0.58 \\
\hline & Damage & $\omega$ & - & 0.0 & 0.0 \\
\hline \multicolumn{2}{|l|}{ Structure multiplication factor from WIPP $25^{\circ} \mathrm{C}$ salt } & SMF & - & - & $0.172^{\mathrm{c}}$ \\
\hline
\end{tabular}

The parameter values are assumed to be the same as the WIPP salt values or adjusted from the WIPP salt value in proportion to the $A_{2}$ value obtained experimentally for Bayou Choctaw salt

${ }^{\mathrm{a}} A_{2}$ multiplication factor to examine the $A_{2}$ factor effect

${ }^{\mathrm{b}} K_{0}$ multiplication factor to examine the $K_{0}$ factor effect

${ }^{\mathrm{c}} S M F=A_{2 \text { BC Salt }} / A_{2}$ WIPP Salt $\cdot A_{1}, B_{1}$, and $B_{2}$ of BC salt are SMF multiples of the corresponding WIPP salt values

Table 5 Material properties of the lithologies encompassing the salt dome used in the analysis (Park et al. 2008)

\begin{tabular}{lllcc}
\hline & Unit & Overburden & Caprock & $\begin{array}{l}\text { Sur- } \\
\text { round- } \\
\text { ing rock }\end{array}$ \\
\hline Young's modulus & $\mathrm{GPa}$ & 0.1 & 15.72 & 35.0 \\
Density & $\mathrm{kg} / \mathrm{m}^{3}$ & 1874 & 2319 & 2500 \\
Poisson's ratio & - & 0.33 & 0.288 & 0.33 \\
\hline
\end{tabular}

Table 6 Material properties of the interbed and interface used in the analysis

\begin{tabular}{llll}
\hline & Unit & Interbed & Interface \\
\hline Young's modulus & $\mathrm{GPa}$ & 0.1 & 0.35 \\
Density & $\mathrm{kg} / \mathrm{m}^{3}$ & 1874 & 2500 \\
Poisson's ratio & - & 0.33 & 0.33 \\
\hline
\end{tabular}

the density and Poisson's ratio of the surrounding rock are used for the pseudo-material of the interface. To implement a soft element, $1 \%$ of the surrounding rock's elastic modulus is used for the interface. The mechanical properties used in the analysis are listed in Table 6.

\section{Parameter Effect}

\subsection{Caveman}

Cavern volume closure as a function of time is not a directly measured quantity, i.e., day-to-day volume closure due to creep cannot be monitored at the field. Daily cavern volume closure is estimated indirectly using a cavern pressure monitoring code named CAVEMAN (Ballard and Ehgartner 2000). Many of the numerous thermal and mechanical parameters in CAVEMAN have been optimized to produce the best match between the field historical data and the model predictions. Therefore, CAVEMAN predictions are used as 'data' for calibration purposes in this study. 
Fig. 8 Volumetric closure normalized to initial cavern volume calculated using the baseline parameter values and CAVEMAN predictions for $\mathrm{BC}-15$ and 18
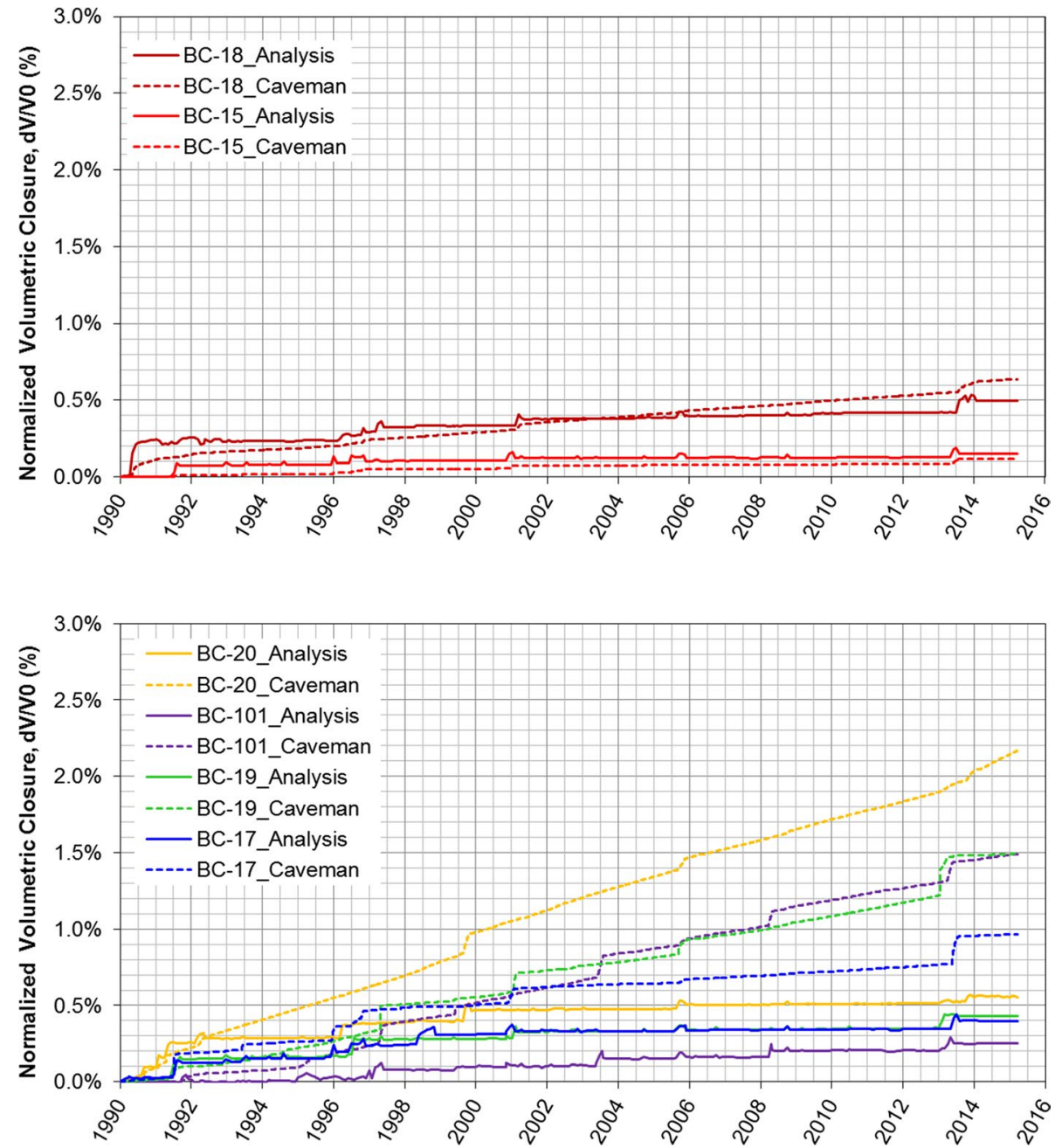

Fig. 9 Volumetric closure normalized to initial cavern volume calculated using the baseline parameter values and CAVEMAN predictions for BC-17, 19,20 , and 101

\subsection{Baseline}

Figures 8 and 9 show the predicted decrease in storage volumes of BC SPR caverns with the CAVEMAN predictions. The solid curves indicate the normalized volumetric closure when the parameter values in Table 4 with $A_{2} F=1$ and $K_{0} F=1$ are used. The dashed curves indicate the normalized volumetric closure predicted from CAVEMAN. The predictions for $\mathrm{BC}-15$ and 18 are close to each other but are much different for other caverns. The effective creep rates in volume loss percentage per year differ with cavern locations (Linn 1997). Therefore, the parameter values in M-D model need to be optimized to produce the best match between the CAVEMAN and model predictions.

To calibrate the parameter values, we need to be aware how each parameter affects the cavern volumetric closure. The structure factors, $A$ 's and $B$ 's in Eqs. (2)-(4), affect the steady-state creep rates, and $K_{0}$ in Eq. (8) affects the transient strain rates as mentioned in Sect. 5.1. Because all of the creep tests were conducted at relatively low stress and low temperature, the creep in terms of the structure factor of just one of the three mechanisms involved in salt creep can be characterized. This is the undefined or empirical mechanism with the structure factor $A_{2}$ (Munson 1998). Equation (3) represents the strain rate for an empirically specified but undefined mechanism at low temperatures and low stresses. The structure factor, $A_{1}$ in Eq. (2), may also need to be considered, but for the stress and temperature regimes where the SPR caverns are located, mechanism 2 [Eq. (3)] tends to dominate mechanism 1 [Eq. (2)] (Sobolik 2015). Therefore, the effect of $A_{2}$ in Eq. (2) will be examined for the steadystate creep in this study. The only parameter value that has no basis in the experimental data or a logical extension, and is therefore an assumed value, is the value of $K_{0}$, which may indeed depend strongly upon specific salt material (Munson 1998). Therefore, the effect of $K_{0}$ will be investigated for the transient strain.

\section{$6.3 A_{2}$ Effect}

The value of $A_{2}$ (Eq. 3) obtained experimentally from BC salt and the value of $K_{0}$ (Eq. 8) obtained from WIPP salt 
Fig. 10 Predicted cavern volumetric closure normalized to initial volume of $\mathrm{BC}-19$ with various $A_{2}$ multiplication factors $\left(A_{2} F\right)$ when $K_{0}$ multiplication factor $K_{0} F=0.1$
Fig. 11 Relationship between $\mathrm{A}_{2} \mathrm{~F}$ and slopes in the time interval between $1 / 2 / 2006$ and $12 / 30 / 2012(6 / 2 / 2008$ and $12 / 30 / 2012$ for BC-101)
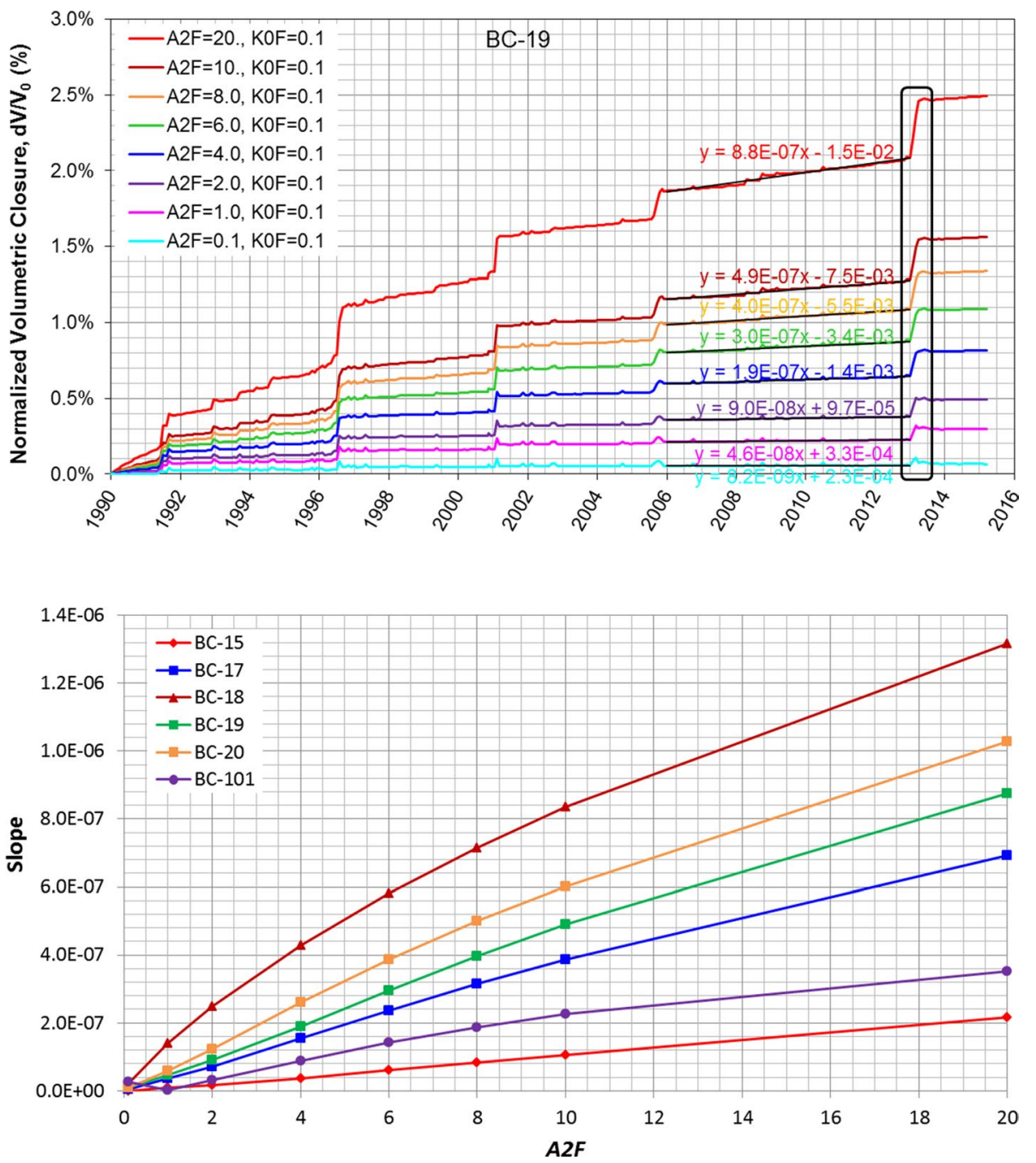

are used for the baseline values. To adjust the magnitude of $A_{2}$ and $K_{0}$, multiplication factors $A_{2} F$ and $K_{0} F$ are defined, respectively. The $A_{2} F$ and $K_{0} F$ values of the salt dome and salt drawdown skins surrounding each SPR cavern have been evaluated through a number of back analyses.

To examine the effect of changing $A_{2}$ on cavern volumetric closure, the normalized volumetric closures for six SPR caverns are calculated with several $A_{2}$ values, while other parameter values are not changed. The magnitude of the sudden increases (called 'jump' hereafter) in cavern volumetric closure at workovers is a function of $A_{2}$ but also of the transient creep phenomenon, which is governed by the factor $K_{0}$ in Eq. (8). A workover is a cavern operation when the wellhead pressure is reduced to zero so that inspection, testing, or other invasive operations in the cavern can be performed. Certain types of borehole and cavern testing have requirements to be performed at 5-year intervals, which in turn is the typical workover schedule. Additional workovers may be performed as operational circumstances necessitate. The slopes of the curves calculated from the analysis for
BC-17, 19, 20, and 101 as shown in Fig. 9 are much smaller than CAVEMAN's. Thus, ten times the constant $A_{2}$ value is used as a start value for the calibration. Then, it makes the magnitude of jump larger than CAVEMAN's, so $10 \%$ constant of $K_{0}$ value is used as a start value to reduce the magnitude. The parameter values in Table 4 with $A_{2} F=10$ and $K_{0} F=0.1$ are used for an ADAGIO input deck.

Figure 10 shows, as an example, the predicted cavern volumetric closure normalized to the initial volume of BC-19 with various $A_{2}$ multiplication factor $\left(A_{2} F\right)$ values when $K_{0}$ multiplication factor $K_{0} F=0.1$. The linear equation on each curve indicates the trend line (regression) with slope and intercept values in the time interval between $1 / 2 / 2006$ and $12 / 30 / 2012(6 / 2 / 2008$ and 12/30/2012 for BC-101) because the period between workovers is longest.

Figure 11 shows the relationship between the slope and $A_{2} F$ for six SPR caverns. The slope increases nearly linearly as the $A_{2} F$ increases. However, the increase rate is different for each cavern, i.e., not uniform throughout the salt dome. Figure 11 is used to calibrate the value of $A_{2}$ and then match 
Fig. 12 Relationship between $A_{2} F$ and magnitude of jump due to the workover
Fig. 13 Predicted cavern volumetric closure normalized to initial volume with various $K_{0}$ multiplication factors $\left(K_{0} F\right)$ when $A_{2}$ multiplication factor $A_{2} F=10$
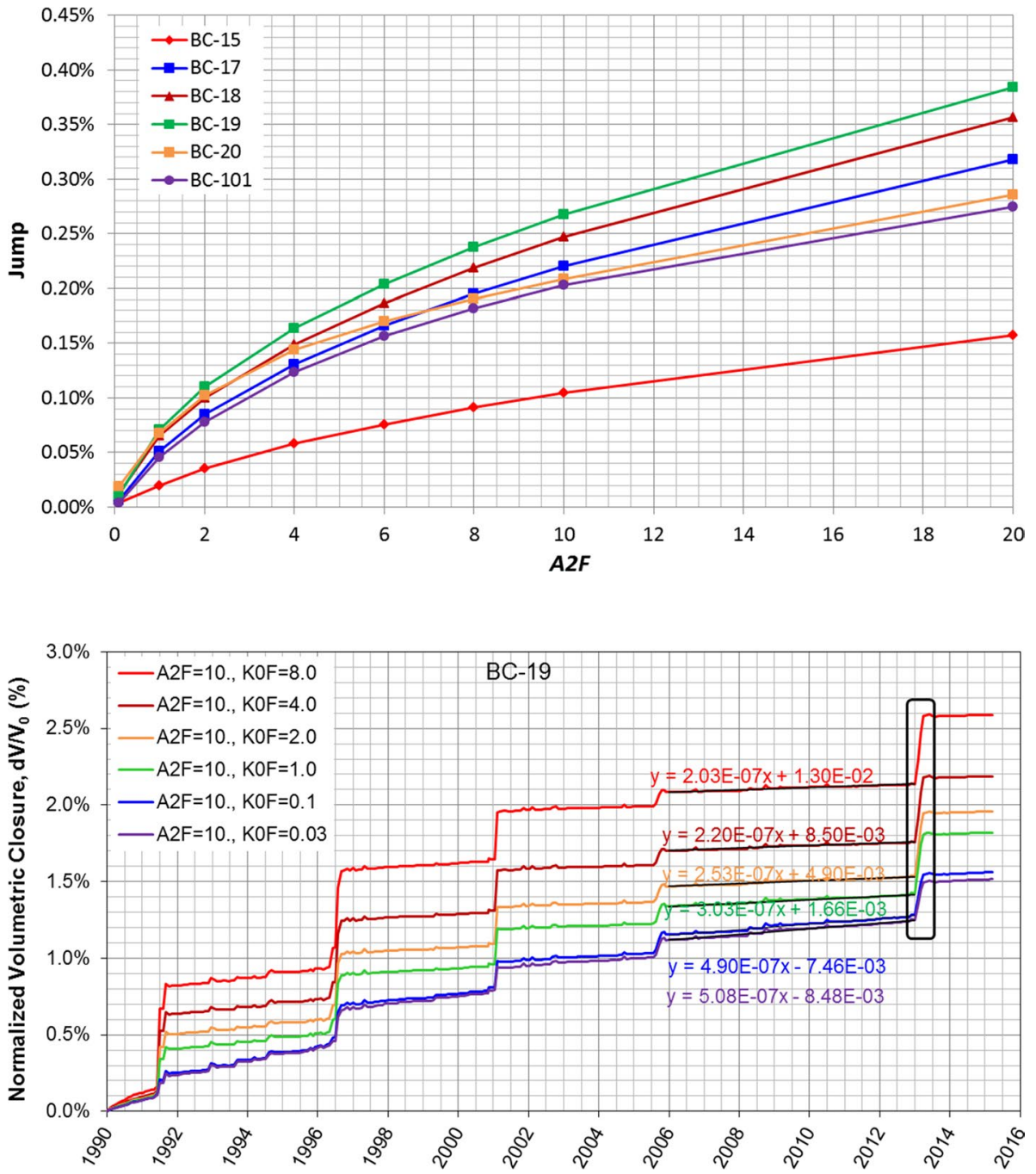

the cavern volumetric closure calculated from the analysis to the CAVEMAN predictions.

To examine how $A_{2}$ affects the jump, the differences between the normalized volumetric closures before and after the workover (indicated by the rectangular in Fig. 10) are calculated from the curves. The magnitudes are changed with $A_{2} F$ values as shown in Fig. 12. The curve for each cavern has a trend. However, the increase rate for each cavern is different, i.e., not uniform in the salt dome like the slope trend.

As shown in Figs. 11 and 12, the $A_{2} F$ values for the salt dome and cavern skins (salt around caverns as shown in Fig. 3) are calibrated to match the model predictions to the CAVEMAN's.

\section{$6.4 K_{0}$ Effect}

In a similar manner, the normalized volumetric closures for six SPR caverns are calculated with several $K_{0}$ values, while other parameter values are not changed to examine the effect of $K_{0}$.

Figure 13 shows the predicted cavern volumetric closure normalized to the initial volume of BC-19, as an example, with various $K_{0}$ multiplication factor values $\left(K_{0} F\right)$ when the $A_{2}$ multiplication factor $A_{2} F=10$. The linear equation on each curve indicates the trend line (regression) with slope and intercept values in the time interval between 1/2/2006 and 12/30/2012 (6/2/2008 and 12/30/2012 for BC-101).

Figure 14 shows the relationship between the slope and $K_{0} F$ for six SPR caverns. The slope decreases with $K_{0} F$, and the decrease rate tends to decrease further as $K_{0} F$ increases. The slope decrease rate is different for each cavern, i.e., not uniform throughout the salt dome.

To examine how $K_{0}$ affects the jumps in cavern volumetric closure at workovers, the differences between the normalized volumetric closures before and after the workover (indicated by the rectangular in Fig. 13) are calculated from the curves. The difference indicates the magnitude of jump due to the workover. The magnitudes are changed with $K_{0} F$ 
Fig. 14 Relationship between $K_{0} F$ and slopes of trend lines in the time interval between $1 / 2 / 2006$ and $12 / 30 / 2012$ $(6 / 2 / 2008$ and $12 / 30 / 2012$ for BC-101)

Fig. 15 Relationship between $K_{0} F$ and magnitude of jump due to the workover
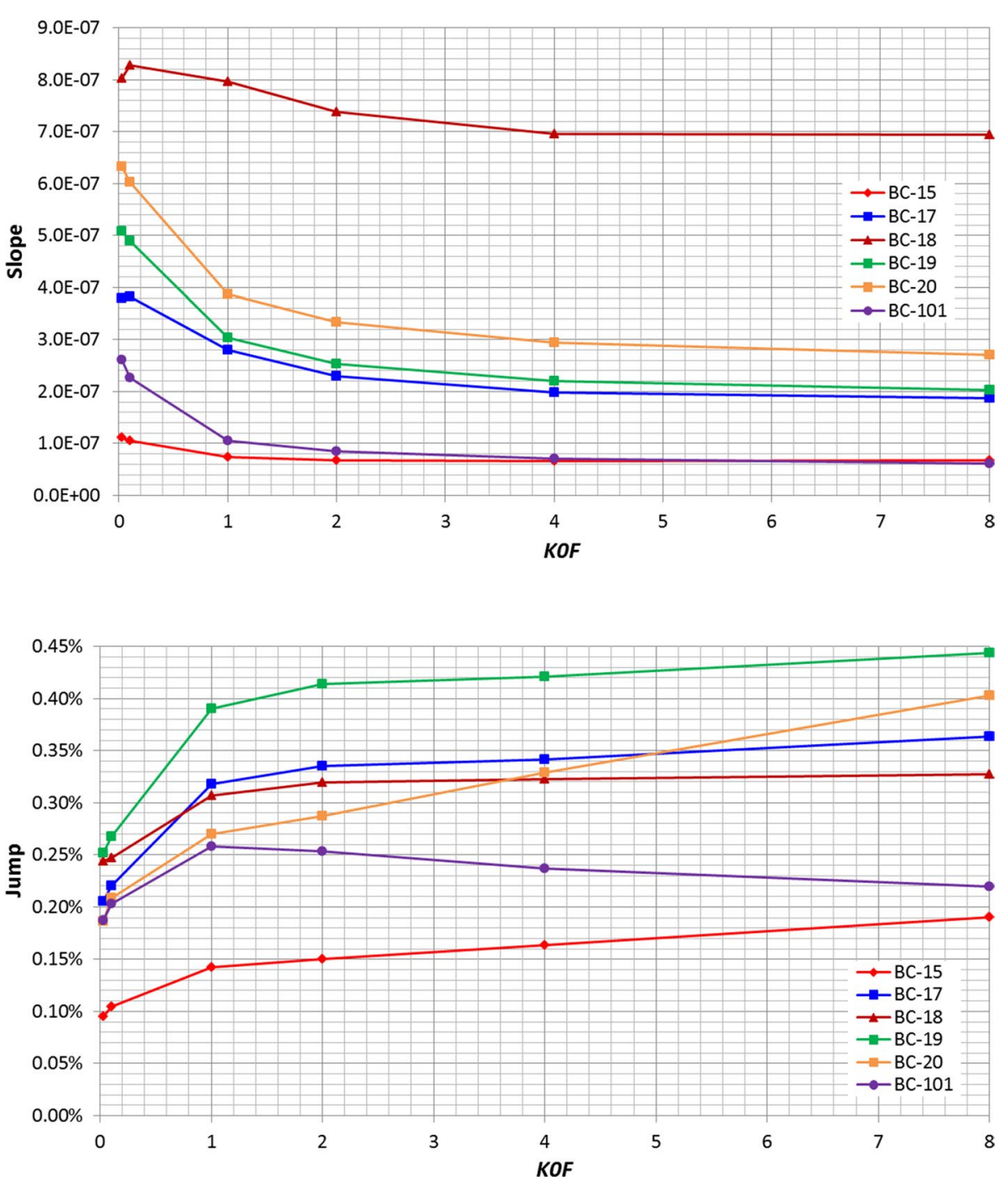

values as shown in Fig. 15. The magnitude increases with $K_{0} F$ value increases.

As shown in Figs. 14 and 15, $K_{0} F$ value for the salt dome and cavern skins is calibrated to match the model predictions to the CAVEMAN's. Figures 11, 12, 14, and 15 are used as a trend to calibrate the values of $A_{2}$ and $K_{0}$ for other SPR sites.

\section{Model Calibration}

Based on the relationships in Figs. 11, 12, 14, and 15, the values of $A_{2} F$ and $K_{0} F$ are calibrated through a number of back analyses and determined as listed in Table 7. The volumetric closure normalized to initial volumes of six SPR caverns calculated from CAVEMAN (dashed curves in Figs. 8 and 9) is used as a back analysis standard.

The values of $A_{2} F$ and $K_{0} F$ are determined through two steps:
Table 7 Multiplication factors applied to the $A_{2}$ and $K_{0}$ values listed in Table 4

\begin{tabular}{lcc}
\hline Cavern ID & $A_{2} F$ & $K_{0} F$ \\
\hline Salt except SPR cavern skins & $\mathbf{1 0 . 0}$ & $\mathbf{0 . 1 0}$ \\
BC-15 salt skins & 0.01 & 0.03 \\
BC-17 salt skins & 0.12 & 0.10 \\
BC-18 salt skins & 0.04 & 0.03 \\
BC-19 salt skins & 10.0 & 0.10 \\
BC-20 salt skins & 10.0 & 0.10 \\
BC-101 salt skins & 10.0 & 0.10 \\
BC-102 salt skins & 10.0 & 0.10 \\
\hline
\end{tabular}

The bold values indicate the parameter values for the entire salt dome except the cavern skins

In the first step, the values of entire salt dome are determined. When $A_{2} F=1.0$ and $K_{0} F=1.0$, the increase rates of normalized volumetric closure calculated from CAVEMAN 
Fig. 16 Volumetric closure normalized to initial cavern volumes calculated using $A_{2} F=10$ and $K_{0} F=0.1$ with CAVEMAN predictions for six SPR caverns
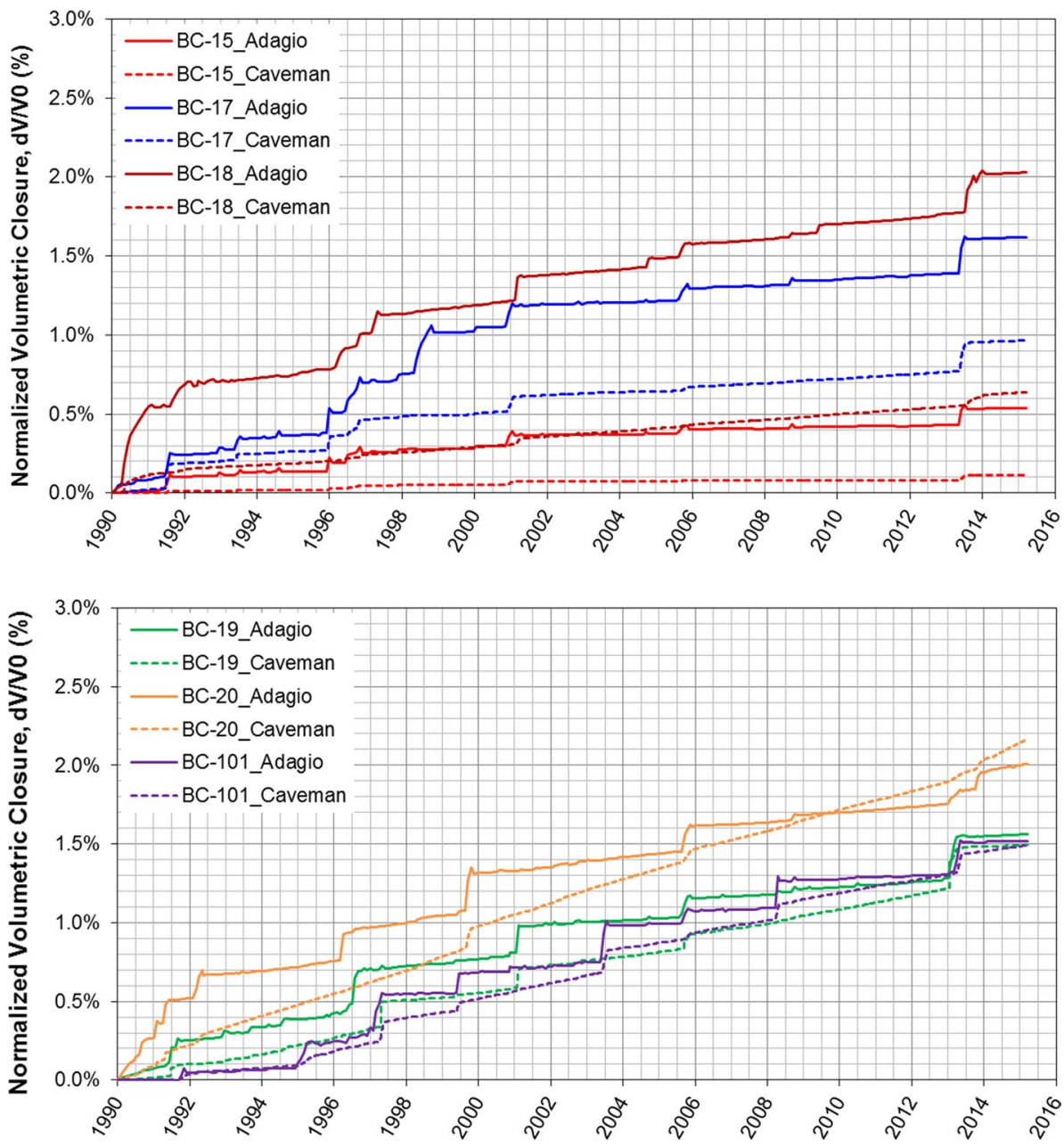

are much larger than those from the analyses except BC-15 and 18 as shown in Figs. 8 and 9. The curve slopes need to be increased without increasing the magnitude of the jump. Considering the $A_{2} F$ and $K_{0} F$ effects in Sects. 6.3 and 6.4, $A_{2} F$ and $K_{0} F$ are determined as 10 and 0.1 , respectively, through a number of back analyses. Figure 16 shows the volumetric closures normalized to initial cavern volumes calculated using $A_{2} F=10$ and $K_{0} F=0.1$ with CAVEMAN predictions for six SPR caverns. The solid and dashed curves indicate the results using ADIGIO and CAVEMAN, respectively. For both the CAVEMAN and ADAGIO values, the long time periods with relatively straight slopes in the plots represent periods of normal operating conditions (steadystate periods), whereas the sudden jumps in cavern closure represent periods (usually workovers) when the wellhead pressure was much lower than normal. The ADIGIO results for BC-19, 20, and 101 are matched well to CAVEMAN's, but the increase rates from the ADAGIO for BC-15, 17, and 18 are larger than from the CAVEMAN.

In the second step, the values of the salt skins (as shown in Fig. 3) of six SPR caverns are determined. To reduce the increase rates of normalized volumetric closure of BC-15,
17, and 18 , the $A_{2} F$ and $K_{0} F$ of cavern skins are calibrated as shown in Figs. 11, 12, 14, and 15. Finally, the values of $A_{2} F$ and $K_{0} F$ of BC-15, 17, and 18 cavern skins have been determined as listed in Table 7 through a number of ADAGIO back analysis runs. BC-102 was previously owned by Boardwalk. The DOE purchased BC-102 to use for SPR in 2012. The wellhead pressure has been recorded since 11/9/2012, so CAVEMAN predictions only exist since then, which is too short of a period to catch the trend of cavern volumetric closure. Therefore, the multiplication factor values of BC-102 skins assume to be the same as BC-101's because two caverns are close to each other and the depths of cavern tops are similar.

Figure 17 shows the volumetric closure normalized to initial cavern volumes calculated using calibrated $A_{2} F$ and $K_{0} F$ in Table 7 with CAVEMAN predictions for six SPR caverns. The analysis results for six SPR caverns match up well to CAVEMAN's. However, a gap between them still exists. CAVEMAN assumes that caverns are right circular cylinders rather than real geometries as in this model. Available cavern height and cavern volume information were used to calculate an effective radius for each cavern (Ballard and 
Fig. 17 Volumetric closure normalized to initial cavern volumes calculated using calibrated $A_{2} F$ and $K_{0} F$ in Table 7 with CAVEMAN predictions for six SPR caverns
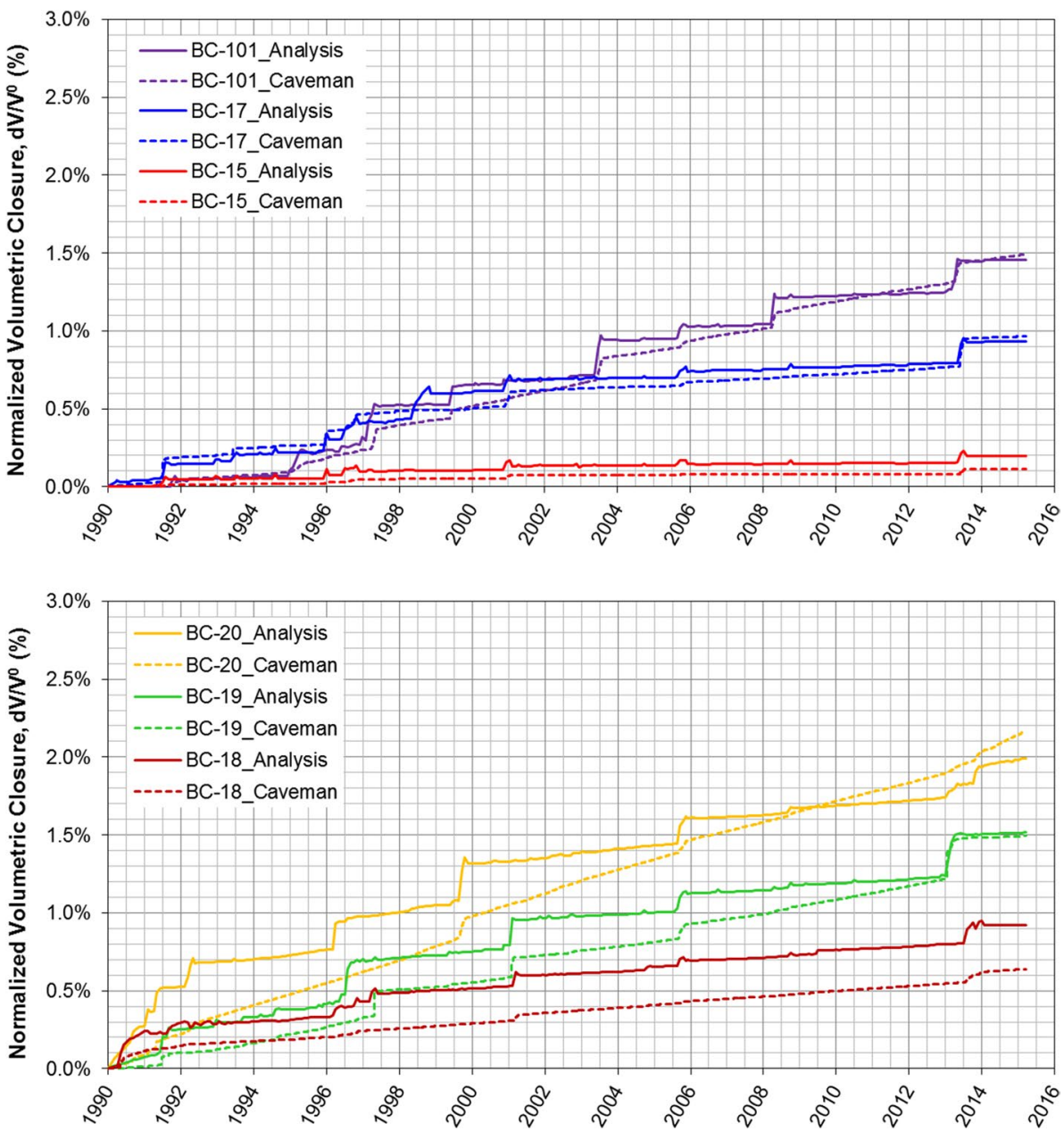

Ehgartner 2000). The discrepancies between the predictions from ADAGIO and CAVEMAN for BC-18, 19, and 20 are larger than other caverns because the cavern shapes are farthest away from a cylinder used in CAVEMAN and contain disk shapes indicated by ellipses as shown in Fig. 18. This implies the predictions from this model may be closer to the real geomechanical behavior than CAVEMAN's. Therefore, the numerical finite element model in this paper can reliably predict geomechanical behavior of salt containing cavern cavities.

\section{Summary and Conclusions}

A new numerical analysis model has been constructed that consists of a mesh that effectively captures the geometries of the BC SPR site and M-D salt constitutive model using the daily data of wellhead pressure and oil-brine interface depth obtained from the field office. Calibration exercises have been performed in an attempt to match model predictions of cavern volumetric closure with field measurements.
The salt creep rate is not uniform across the salt dome, and the creep test data of the BC salt are limited. Therefore, a model calibration is necessary to correctly simulate the geomechanical behavior of the salt dome.

The cavern volumetric closures of the BC SPR caverns calculated from CAVEMAN are used for the field baseline standard. The structure factor, $A_{2}$, and transient strain limit factor, $K_{0}$, in the M-D constitutive model were used as calibration factors. The $A_{2}$ value obtained experimentally from BC salt and $K_{0}$ value of WIPP salt are used for the baseline values. To adjust the magnitude of $A_{2}$ and $K_{0}$, multiplication factors $A_{2} F$ and $K_{0} F$ are defined, respectively. The $A_{2} F$ and $K_{0} F$ values of the salt dome have been determined to be 10.0 and 0.1 , respectively, through a number of back analyses. The value for the salt skins surrounding each SPR cavern has also been determined to meet the different salt creep rates at each cavern location. This skin difference may be a result of a disturbed rock zone (DRZ) formed around the cavern. The deformation of damaged rock will be dramatically different than intact rock.

The volumetric closures normalized by initial cavern volumes calculated from the new model correspond to the 
Fig. 18 Side views of SPR caverns in Bayou Choctaw salt dome (vertical and horizontal scales are equal, not in true relationship to one another spatially, except for Cavern 15 and 17)

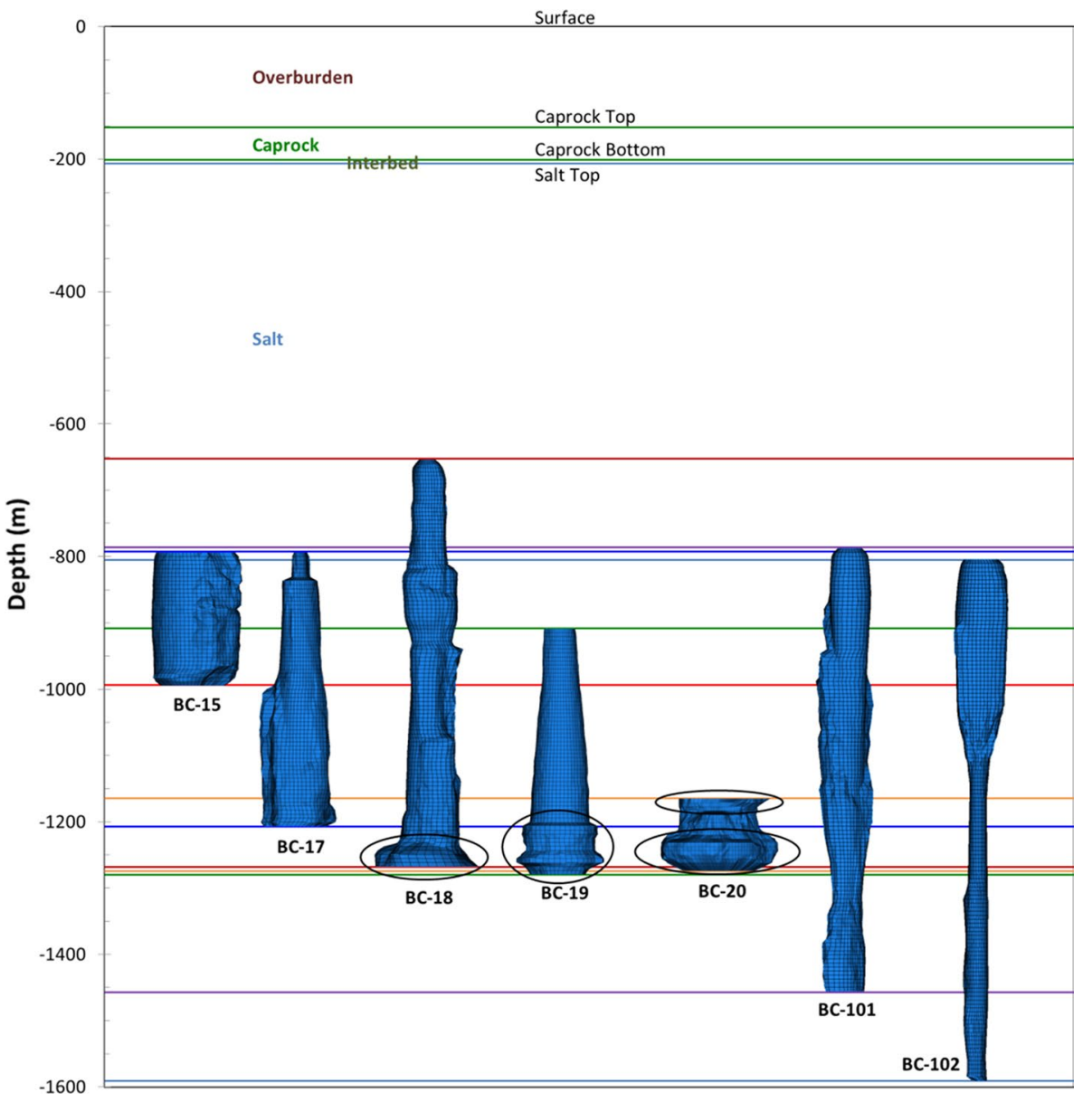

predictions from CAVEMAN for six SPR caverns. Therefore, the new model can reliably predict geomechanical behavior of the salt dome containing 26 caverns. The geological concerns issuing from the $\mathrm{BC}$ site will be explained from this model in a subsequent paper.

Acknowledgements Sandia National Laboratories is a multimission laboratory managed and operated by National Technology and Engineering Solutions of Sandia LLC, a wholly owned subsidiary of Honeywell International Inc. for the US Department of Energy's National Nuclear Security Administration under contract DE-NA0003525. This work is supported by Leigh Cunningham of Sandia, manager, and Anna C. Snider Lord of Sandia, project manager. As always, the support of Diane Willard and Wayne Elias of DOE is greatly appreciated. Paul Malphurs of DOE is also greatly appreciated, as is his comprehensive review of this report. This report has been improved by these individuals.

Open Access This article is distributed under the terms of the Creative Commons Attribution 4.0 International License (http://creativecomm ons.org/licenses/by/4.0/), which permits unrestricted use, distribution, and reproduction in any medium, provided you give appropriate credit to the original author(s) and the source, provide a link to the Creative Commons license, and indicate if changes were made.

\section{References}

Ballard S, Ehgartner BL (2000) CAVEMAN version 3.0: system for SPR cavern pressure analysis, SAND2000-1751, Sandia National Laboratories, Albuquerque, NM 87185-0750

Carmichael RS (1984) CRC handbook of physical properties of rocks. CRC (Chemical Rubber Company) Press, Inc., Boca Raton

Dames, Moore (1978) Determination of physical properties of salt and caprock, Bayou Choctaw Salt Dome, Iberville Parish, Louisiana: in PB/KKB, Inc., 1978f, salt dome geology and cavern stability, Bayou Choctaw, Louisiana, Final Report, Appendix, prepared for the U.S. Department of Energy

Hoffman EL (1992) Investigation of analysis assumptions for SPR calculations, memo to J. K. Linn dated February 7, 1992, Sandia National Laboratories, Albuquerque, New Mexico

Hogan RG (1980) Strategic petroleum reserve (SPR) geological site characterization report Bayou Choctaw Salt Dome, SAND807140. Sandia National Laboratories, Albuquerque

Linn JK (1997) Memorandum to R.E. Myers, November 25, 1997 with attachment on "SPR Ullage Study" by B.L. Ehgartner, Sandia National Laboratories, Albuquerque, New Mexico

Munson DE (1979) Preliminary deformation-mechanism map for salt (with application to WIPP), SAND70-0079. Sandia National Laboratories, Albuquerque

Munson DE (1998) Analysis of multistage and other creep data for domal salts, SAND98-2276. Sandia National Laboratories, Albuquerque 
Munson DE, Dawson PR (1979) Constitutive Model for the low temperature creep of salt (with application to WIPP). SAND79-1853. Sandia National Laboratories, Albuquerque

Munson DE, Dawson PR (1982) A Transient creep model for salt during stress loading and unloading. SAND82-0962. Sandia National Laboratories, Albuquerque

Munson DE, Dawson PR (1984) Salt constitutive modeling using mechanism maps. In: 1st international conference on the mechanical behavior of salt. Trans Tech Publications, Clausthal, Germany, pp 717-737

Munson DE, Fossum AF, Senseny PE (1989) Advances in resolution of discrepancies between predicted and measured in situ WIPP room closures. SAND88-2948. Sandia National Laboratories, Albuquerque

Park BY (2014) Interbed modeling to predict wellbore damage for Big Hill strategic petroleum reserve. J Rock Mech Rock Eng 2014(47):1551-1561. https://doi.org/10.1007/s00603-014-0572-2

Park BY, Ehgartner BL (2012) Expansion analyses of strategic petroleum reserve in Bayou Choctaw-revised locations, SAND-20116061C. In: 7th conference on the mechanical behavior of salt held in Paris, France, April 16-19, 2012

Park BY, Roberts BL (2015) Construction of hexahedral elements mesh capturing realistic geometries of Bayou Choctaw SPR site, SAND2015-7458. Sandia National Laboratories, Albuquerque

Park BY, Ehgartner BL, Herrick CG, Lee MY (2008) Numerical simulation evaluating the structural stability of the strategic petroleum reserve (SPR) in Bayou Choctaw Salt Dome, USA. In: The 42nd
U.S. rock mechanics symposium and the 2nd U.S.-Canada rock mechanics symposium, held in San Francisco, CA, June 28-July 3. ARMA 08-150

Park BY, Ehgartner BL, Herrick CG (2011) Allowable pillar to diameter ratio for strategic petroleum reserve caverns, SAND20111561C. In: The 45th US rock mechanics/geomechanics symposium held in San Francisco, CA, June 26-29. ARMA 11-219

Park BY, Roberts BL, Sobolik SR (2017) Construction of hexahedral finite element mesh capturing realistic geometries of a petroleum reserve. J Finite Elem Anal Des 135:68-78. https://doi. org/10.1016/j.finel.2017.07.007

Rautman CA, Looff KM, Duffield JB (2009) A three-dimensional geometric model of the Bayou Choctaw Salt Dome, Southern Louisiana, using 3-D seismic data, OUO SAND2009-1037. Sandia National Laboratories, Albuquerque

Roberts BL (2015) BC dome seismic image, E-mail from B.L. Roberts to B.Y. Park dated 2/5/2015. Sandia National Laboratories, Albuquerque, New Mexico

Sandia (2015) CUBIT 15.0 user documentation. https://cubit.sand ia.gov/public/15.0, Sandia National Laboratories, Albuquerque, New Mexico

Sobolik SR (2015) Analysis of cavern and well stability at the West Hackberry SPR Site using a full-dome model, SAND2015-7401. Sandia National Laboratories, Albuquerque

Wawersik WR, Zeuch DH (1984) Creep and creep modeling of three domal salts-a comprehensive update, SAND84-0568. Sandia National Laboratories, Albuquerque 